\title{
Development and characterization of an ice-selecting pumped counterflow virtual impactor (IS-PCVI) to study ice crystal residuals
}

\author{
Naruki Hiranuma ${ }^{1}$, Ottmar Möhler ${ }^{1}$, Gourihar Kulkarni ${ }^{2}$, Martin Schnaiter ${ }^{1},{\text { Steffen } \operatorname{Vogt}^{1}}^{1}$, Paul Vochezer $^{1}$, \\ Emma Järvinen $^{1}$, Robert Wagner ${ }^{1}$, David M. Bell ${ }^{2}$, Jacqueline Wilson ${ }^{2}$, Alla Zelenyuk ${ }^{2}$, and Daniel J. Cziczo ${ }^{3}$ \\ ${ }^{1}$ Institute of Meteorology and Climate Research - Atmospheric Aerosol Research, Karlsruhe Institute of \\ Technology, Karlsruhe, Germany \\ ${ }^{2}$ Pacific Northwest National Laboratory, Richland, WA, USA \\ ${ }^{3}$ Earth, Atmospheric and Planetary Sciences, Civil and Environmental Engineering, Massachusetts Institute of \\ Technology, Cambridge, MA, USA
}

Correspondence to: Naruki Hiranuma (seong.moon@kit.edu)

Received: 28 March 2016 - Published in Atmos. Meas. Tech. Discuss.: 22 April 2016

Revised: 15 July 2016 - Accepted: 18 July 2016 - Published: 18 August 2016

\begin{abstract}
Separation of particles that play a role in cloud activation and ice nucleation from interstitial aerosols has become necessary to further understand aerosol-cloud interactions. The pumped counterflow virtual impactor (PCVI), which uses a vacuum pump to accelerate the particles and increase their momentum, provides an accessible option for dynamic and inertial separation of cloud elements. However, the use of a traditional PCVI to extract large cloud hydrometeors is difficult mainly due to its small cut-size diameters $(<5 \mu \mathrm{m})$. Here, for the first time we describe a development of an ice-selecting PCVI (IS-PCVI) to separate ice in controlled mixed-phase cloud system based on the particle inertia with the cut-off diameter $\geq 10 \mu \mathrm{m}$. We also present its laboratory application demonstrating the use of the impactor under a wide range of temperature and humidity conditions. The computational fluid dynamics simulations were initially carried out to guide the design of the IS-PCVI. After fabrication, a series of validation laboratory experiments were performed coupled with the Aerosol Interaction and Dynamics in the Atmosphere (AIDA) expansion cloud simulation chamber. In the AIDA chamber, test aerosol particles were exposed to the ice supersaturation conditions (i.e., $\mathrm{RH}_{\mathrm{ice}}>100 \%$ ), where a mixture of droplets and ice crystals was formed during the expansion experiment. In parallel, the flow conditions of the IS-PCVI were actively controlled, such that it separated ice crystals from a mixture of ice crystals and cloud droplets, which were of diameter $\geq 10 \mu \mathrm{m}$. These large ice crystals were passed through the heated evap-
\end{abstract}

oration section to remove the water content. Afterwards, the residuals were characterized with a suite of online and offline instruments downstream of the IS-PCVI. These results were used to assess the optimized operating parameters of the device in terms of (1) the critical cut-size diameter, (2) the transmission efficiency and (3) the counterflow-toinput flow ratio. Particle losses were characterized by comparing the residual number concentration to the rejected interstitial particle number concentration. Overall results suggest that the IS-PCVI enables inertial separation of particles with a volume-equivalent particle size in the range of $\sim 10$ $30 \mu \mathrm{m}$ in diameter with small inadvertent intrusion $(\sim 5 \%)$ of unwanted particles.

\section{Introduction}

\subsection{Background}

The glaciation of supercooled clouds through various ice nucleation (IN) processes is an important atmospheric process affecting the formation of precipitation after a series of secondary processes and the Earth's energy budget (Boucher et al., 2013). Currently, the climatic impact of ice-nucleating particles (INPs) is being reassessed due to increasing evidence of their diversity and potential ability to influence cloud properties (e.g., Hoose and Möhler, 2012; Murray et al., 2012; Després et al., 2012; O'Sullivan et al., 2015; Wil- 
son et al., 2015). However, our knowledge of the atmospheric INP abundance and their identities as well as sources remains scarce (e.g., Knopf et al., 2014). The analysis of ice residual particles, which are mainly leftover INPs after evaporating the water content (DeMott et al., 2003), can help to answer this question.

Recently, it has been found that the crystalline structures of Arizona test dust particles have the innate advantage of nucleating ice over other aerosols that lack these suitable properties (Kulkarni et al., 2015). Observations of ice crystal residual particles from a limited time segment of field studies suggest an apparent increase in the certain types of compositions (i.e., biological material), which are known as a good INP (e.g., Pratt et al., 2009; Prenni et al., 2009; Huffman et al., 2013). Nevertheless, further experimental work and comprehensive analyses of the INPs' physico-chemical properties are important to develop representative IN parameterizations and resemble the atmospheric representation of INPs. In typical mixed-phase clouds over the Arctic, continental and maritime environment, the average concentration of cloud particles (i.e., sum of droplets and ice crystals in the volume diameter range of $2-47 \mu \mathrm{m}$ ) is in the range of 10 $100 \mathrm{~cm}^{-3}$, and the mean volume diameter of cloud particles in liquid- and ice clouds is $10-12$ and $20-35 \mu \mathrm{m}$, respectively (Korolev et al., 2003). Here, separating ice residuals from large droplets without a substantial influence of artifacts (e.g, transmission of interstitial particles) is a challenge, and the development of such a technique is a key to elucidating true identities of INPs.

\subsection{Development of the counterflow virtual impactors}

The counterflow virtual impactor (CVI), which was originally developed for airborne sampling by Ogren et al. (1985), has widely been used to virtually isolate cloud elements from trace gas or interstitial particles. In particular, the aircraft CVI enabled the collection of droplet and ice crystals that are imparted into the system as a result of the motion of an aircraft and to subsequently sample their residuals after evaporation of water. In addition to its primary function as an inertial particle separator, the CVI simultaneously functions as a particle concentrator, in which an enhancement factor (EF) is determined as the ratio of input and output flow (Hayden et al., 2008). Further, by coupling the CVI with other online and offline analytical techniques, those residual samples can be analyzed for identifying their abundance and physicochemical properties (Twohy et al., 1997; Twohy and Anderson, 2008).

Since 1980s, a series of design updates has been applied to improve the overall performance of the CVI; e.g., enhance the transmission efficiency of residuals and minimize artifacts (e.g., Noone et al., 1988; Anderson et al., 1993; Schwarzenböck et al., 2000; Chen et al., 2005; Hayden et al., 2008; Berg et al., 2009; Shingler et al., 2012). These efforts have led to collect a variety of cloud residual sam- ples from various types of atmospheric clouds, such as cirrus clouds (Cziczo and Froyd, 2014 and references therein), marine boundary layer clouds (e.g., Crumeyrolle et al., 2013; Gieray et al., 1997; Twohy et al., 2001; De Bock et al., 2000; Hopkins et al., 2008; Russel et al., 2000; Noone et al., 2000), Arctic clouds (Hiranuma et al., 2013), orographic clouds (Kamphus et al., 2010), lower tropospheric mixedphase clouds (Mertes et al., 2001), and convective cumulus clouds (Heymsfield et al., 2005; Matsuki et al., 2010).

Based on the CVI principle, Boulter et al. (2006) developed a pumped CVI (PCVI) as an alternative to the airborne CVI for laboratory applications. Instead of using the motion of an aircraft or a wind tunnel as in the airborne CVI, the PCVI utilizes a vacuum pump to bring a particle-laden flow into the system. This self-governing feature and portability of the PCVI system is especially advantageous over the regular CVI to provide constant residual-laden flows to the downstream instruments during studies in a controlled laboratory setting (China et al., 2015; Hiranuma et al., 2011; Slowick et al., 2011; Crawford et al., 2011; Gallavardin et al., 2008; Kim and Raynor, 2009; Cziczo et al., 2003, 2009; DeMott et al., 2003) and a ground-based field application (Kupiszewski et al., 2015; Worringen et al., 2015; Vogel et al., 2013; Corbin et al., 2012; Richardson et al., 2007). In particular, the separation of small ice crystal residuals $(\sim 4 \mu \mathrm{m})$ from diesel soot has been demonstrated with a combination of a compact ice chamber and the PCVI in China et al. (2015). Moreover, among the aforementioned PCVI studies, Crawford et al. (2011) and Gallavardin et al. (2008) have used the PCVI connected to the Aerosol Interaction and Dynamics in the Atmosphere (AIDA) cloud simulation chamber at the Karlsruhe Institute of Technology (KIT) in Germany. These two studies address the characterization of ice-nucleating dust and carbonaceous particles with respect to their residual size, number and chemical composition by coupling a single particle soot photometer (Crawford et al., 2011) or a single particle mass spectrometer (Gallavardin et al., 2008) deployed downstream of the NOAA-PCVI system. More recently, Kupiszewski et al. (2015) developed a phase discriminating inlet, the so-called "Ice Selective Inlet", by connecting a cyclone impactor and a droplet evaporation unit upstream of a commercial off-the-shelf PCVI (BMI, Model 8100). However, the PCVI itself is not designed for sampling large cloud hydrometeors and, thus, the performance of a PCVI in particular the transmission efficiency (TE) beyond what has previously been characterized (i.e., above $5 \mu \mathrm{m}$ ) is still uncertain. As a caveat, the limitations such as ice shattering and reduced TE because of losses may coincide in the case of upper $5 \mu \mathrm{m}$ particle transmission (Kulkarni et al., 2011). Hence, it is a challenge to study $>10 \mu \mathrm{m}$ diameter cloud elements.

Recently, Kulkarni et al. (2011) suggested design modifications to the nozzle geometry and the collector inlet to improve the TE. To date, these design updates have been reflected in a commercial PCVI. However, a number of limi- 
tations regarding the use of the PCVI had been raised. For example, due to flow restrictions of the instruments and an associated small cut size in the current PCVI $(<5 \mu \mathrm{m}$; Kulkarni et al., 2011), the separation of ice crystals in mixed-phase cloud with droplets as large as a few tens of microns $(<30 \mu \mathrm{m}$ diameter; Miles et al., 2000; Lawson et al., 2011) remains a challenge. Further, "unintentional transmission" of particles due to artifacts, such as wake capture (Pekour and Cziczo, 2011), particle breakup, scavenging, collision, coalescence, fragmentation and/or multiplication, is not well characterized.

\subsection{Objectives}

The current study focuses on the engineering development of a new PCVI, termed the ice-selecting PCVI (IS-PCVI henceforth), to separate cloud elements with the cut-size diameter larger than $\sim 10 \mu \mathrm{m}$ (i.e., more than twice larger than what has been characterized previously; Kulkarni et al., 2011). The computational fluid dynamics (CFD) simulations were performed to guide the design, such that the performance characteristics were simulated with the applicable range of flow and pressure $(P)$ configurations prior to the fabrication and development of the device in the laboratory. Afterwards, a series of experimental validation tests were conducted to understand the actual performance characteristics of the ISPCVI, which was deployed downstream of the AIDA chamber (e.g., Möhler et al., 2005a, b; Niemand et al., 2012), during the Ice Nuclei Research Unit campaign took place in May-June 2013 (INUIT05). The AIDA chamber was used to generate the supercooled droplets, which had $<30 \mu \mathrm{m}$ volume-equivalent diameter $\left(D_{\mathrm{ve}}\right)$, and ice crystals (up to $\sim 50 \mu \mathrm{m} D_{\text {ve }}$ ). These cloud elements were used to diagnose the cut size of the IS-PCVI. In addition, the TE of ice residuals was quantified in comparison to the rejected interstitial particles, and the artifacts specific to the experimental conditions were characterized. Further, we operated online high-resolution single particle mass spectrometers behind the IS-PCVI in the Fifth International Ice Nucleation workshop (FIN-1) to demonstrate the capability and application of such combination for the simulated cloud residual studies. FIN-1 was held at the AIDA facility in KIT in November 2014 to comprehensively address the characterization of size, number and chemical composition of atmospherically relevant INPs by co-locating 10 international groups performing mass spectrometry.

\section{Design of the IS-PCVI setup}

The schematic of the IS-PCVI is shown in Fig. 1. The IS-PCVI is composed of five stainless steel parts, and the scale-relevant design of individual components is depicted in Fig. 2. In order to minimize the impaction losses of the particles within the individual components, the entire inner

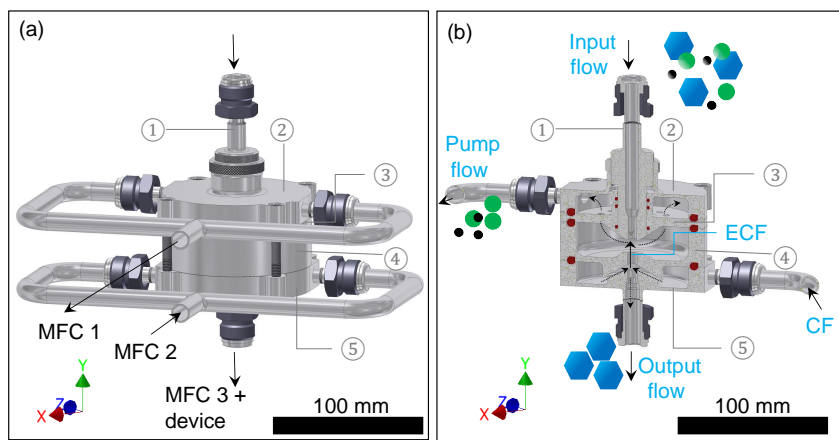

Figure 1. Schematic description of the IS-PCVI outfit (a) and the geometry inside the IS-PCVI (b). The IS-PCVI consists of 5 components; (1) inlet nozzle, (2) top compartment outfitted with the pump flow outlet, (3) rejection plate, (4) middle compartment facilitating the effective counterflow (ECF), and (5) bottom compartment equipped with the counterflow (CF) inlet. The arrows represent the directions of air flows utilized to operate the IS-PCVI. Separation of ice crystals (blue hexagons) from droplet (green spheres) and interstitial particles (black spheres) takes place at the location where the upward effective counterflow $(\mathrm{ECF}=\mathrm{CF}-$ output flow) is shown.

surface of the stainless steel components is electro-polished. The internal volume is $\sim 200 \mathrm{~cm}^{3}$. Note that the total inner air volume is estimated within the boundaries of VCR fittings outfitted to the IS-PCVI. All geometrical parameters of the IS-PCVI used for the flow simulations are summarized in Table 1 . We have modified various parameters for enhancing the transmission of large ice crystals according to the suggestions for design modification made in Kulkarni et al. (2011), which are now reflected in the new commercial PCVI (BMI, Model 8100). For instance, four key improvements have been made in the nozzle geometry, including (1) longer nozzle length, (2) wider nozzle diameter, (3) larger length-to-diameter ratio of the nozzle and (4) shallower inlet converging angle.

A unique feature of the IS-PCVI in comparison to a traditional PCVI is its capability to facilitate large counterflow $\left(\mathrm{CF}>3 \mathrm{~L} \mathrm{~min}^{-1}\right)$ due to its larger dimension (e.g., up-scaled counterflow tube and the other geometry summarized in Table 1). This improvement allows sampling ice crystals larger

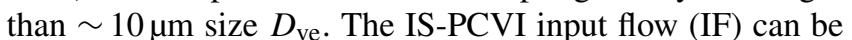
varied from 50 to $100 \mathrm{~L} \mathrm{~min}^{-1}$ depending on the CF-to-IF flow ratio under well-controlled thermodynamic and aerodynamic conditions. The following components have been incorporated to optimize and assess the IS-PCVI performance.

\subsection{Heated-inlet nozzle}

Sampling moist air from the AIDA chamber may lead to ice formation within the IS-PCVI because of the apparent cooling of the sampled air followed by the nozzle surface cooling. Such cooling spontaneously occurs due to the flow acceleration and $P$ reduction around the tip of the venture- 
Table 1. Geometrical parameters of the traditional PCVI and the IS-PCVI derived from the Autodesk Inventor 3-D computer-digitized design.

\begin{tabular}{lll}
\hline Parameter & $\begin{array}{l}\text { PCVI } \\
(\text { Boulter et al., 2006) }\end{array}$ & $\begin{array}{l}\text { IS-PCVI } \\
\text { (this study) }\end{array}$ \\
\hline Total inner air volume & $6.2 \mathrm{~cm}^{3}$ & $193.7 \mathrm{~cm}^{3}$ \\
Nozzle outlet-to-collector inlet length $\left(d_{1}\right)$ & $1.5 \mathrm{~mm}$ & $8.5 \mathrm{~mm}$ \\
Nozzle length $(L)$ & $2.4 \mathrm{~mm}$ & $14.4 \mathrm{~mm}$ \\
Nozzle diameter $\left(D_{\mathrm{n}}\right)$ & $1.4 \mathrm{~mm}$ & $5.5 \mathrm{~mm}$ \\
$L / D_{\mathrm{n}}$ & 1.7 & 2.6 \\
Inlet converging angle $\left(\theta_{1}\right)$ & $45^{\circ}$ (note: $30^{\circ}$ for simulation in & $20^{\circ}$ \\
& Kulkarni et al., 2011) & $15^{\circ}$ \\
Outlet diverging angle $\left(\theta_{2}\right)$ & $45^{\circ}$ & $12.9 \mathrm{~mm}$ \\
Length of diverging conical section towards the & $1.68 \mathrm{~mm}$ & $32.8^{\circ}$ \\
output flow $\left(d_{2}\right)$ & & $45^{\circ}$ tangentially \\
Rejection plate bottom angle $\left(\theta_{\mathrm{p}}\right)$ & $30^{\circ}$ & oriented holes $(\times 12)$ \\
Plate hole geometry & $0^{\circ}$ holes $(\times 12)$ perpendicular to the & 3.8 mm \\
$\left(\theta_{\mathrm{h}}\right)$ & plate plane & \\
Counterflow tube inner diameter & $1.7 \mathrm{~mm}$ & \\
\hline
\end{tabular}

shaped nozzle. This frost formation may clog and sputter (Hiranuma et al., 2011) which may affect the IS-PCVI performance. In order to minimize these issues, the nozzle tip is equipped with $1 \mathrm{~mm}$ diameter micro heating wires $(80 \%$ nickel and $20 \%$ chromium; Fig. 2 a). More specifically, $5 \Omega$ heating wire is installed inside the heat conductive nozzle tip around the converging section over the $35 \mathrm{~mm}$ length. The current through the heating wire is varied depending on the surrounding gas temperature $(T)$ to keep the nozzle surface $T$ above the sampled air $T$ to prevent frost formation and growth. A total of four holes are drilled through the body of the stainless nozzle to insert wires of heating tape and a thermocouple (two holes perpendicular to the particle streamline and the other two holes parallel to the particle streamline). These holes are welded to prevent any leaking issues. The outer wall of the impactor is also heated by a heating-tape and insulated to maintain a constant $T$ of the inner wall of the impactor. Additionally, an external inlet nozzle is deployed upstream of the IS-PCVI to assure laminar flow into the system. This inlet has a conical shape with $32 \mathrm{~mm}$ ID at the entrance and $10 \mathrm{~mm}$ ID on the bottom, fitted to the base of the AIDA interior.

\subsection{Heated-outlets}

Water from ice crystals and droplets is removed in the heated section $\left(>40^{\circ} \mathrm{C}\right)$ downstream of the IS-PCVI outlet. This heated outlet has a total $3 \mathrm{~m}$ length of $10 \mathrm{~mm}$ OD (1 mm wall thickness) stainless steel, covered by the dual layers of heating tape and heat-insulating material outside, and extends to the downstream instruments. Detailed configuration is discussed in Sect. 3.2 (Fig. 3). The dry synthetic air, which has a $T$ of $\sim 20^{\circ} \mathrm{C}$, is used as CF in this study. CF splits into the effective counterflow (ECF) and output flow. Hence, the out-
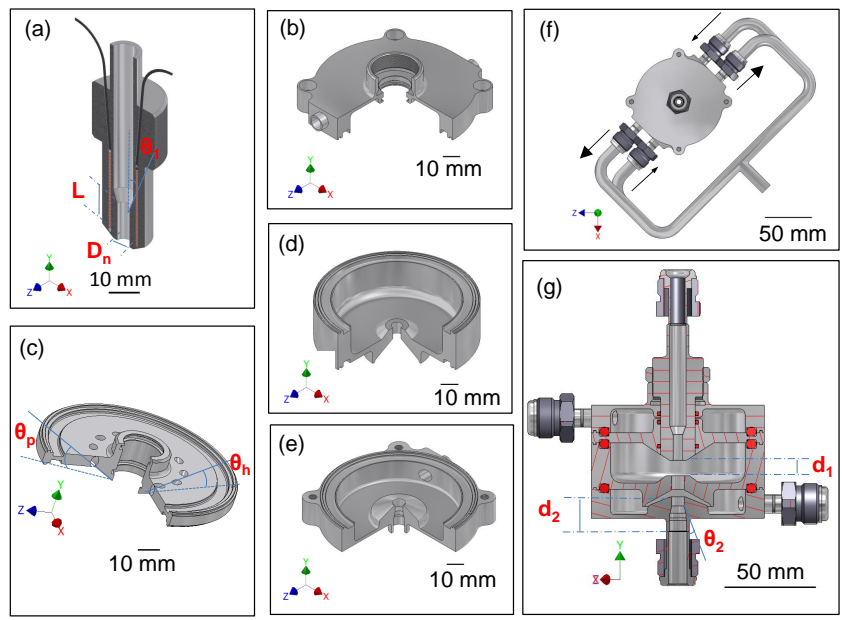

Figure 2. Structure of individual components of the IS-PCVI (from top to bottom) is shown in panels (a) to (e). Panel $\mathrm{f}$ represents the top view, displaying the tangent angle of two pump outlets. This new feature helps minimize the turbulent flow and particle losses. Panel g shows the cross section of the IS-PCVI. A total of eight geometrical parameters used for the CFD simulations (see also Table 1) are also shown.

put flow is composed of this warm and dry air, which helps evaporating or sublimating the water content of particles.

\subsection{Temperature sensors}

In order to continuously monitor the $T$ across the system, we deployed four thermocouples. Two sensors, $T 1$ and $T 2$, are installed in the nozzle; one on the inlet body and the other in the heated-tip as described in Sect. 2.1. A third one, T3, is mounted on the outer surface of the impactor body (nominal $T_{\mathrm{CVI}}$ ), and the last one, $T 4$, is installed in the thermally 


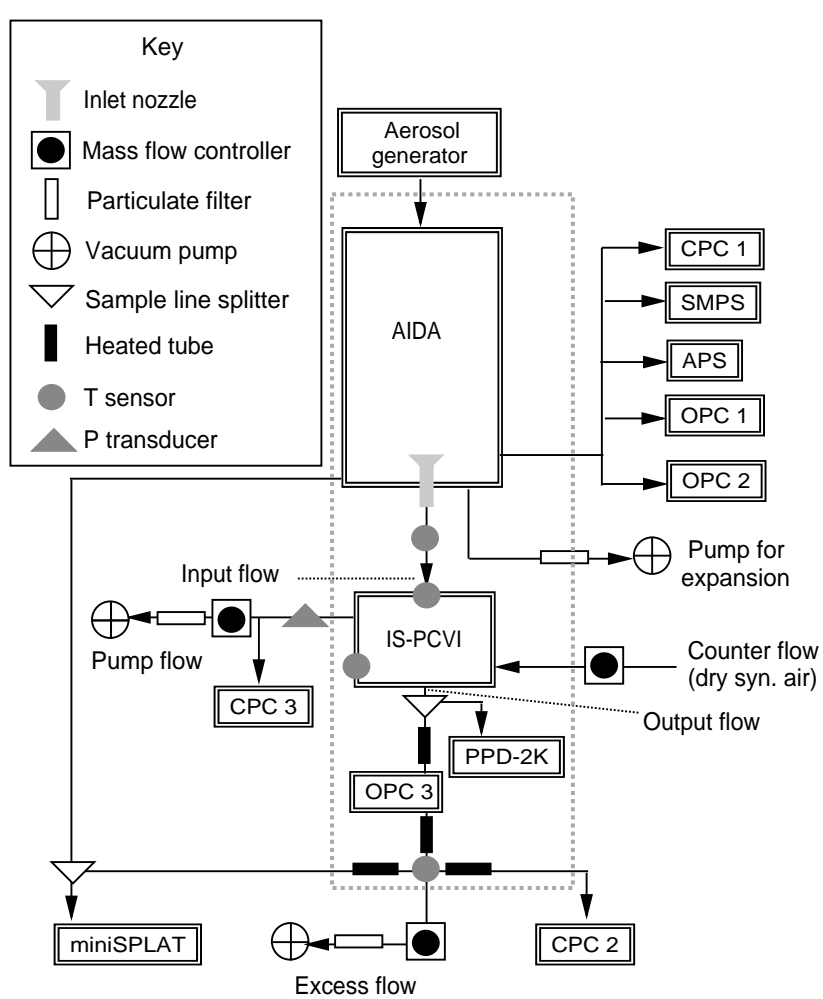

Figure 3. Schematic representation of the experimental setup for validation of the IS-PCVI. The grey dashed line represents the heatinsulating wall of AIDA. Different types of aerosol generators used in this work are summarized in Table S1 in the Supplement.

insulated heated outlet section downstream of the impactor. In addition, the laboratory temperature $\left(T_{\mathrm{LAB}}\right)$ is also monitored as a reference ambient $T$.

\subsection{Pressure transducer}

Due to the venture-shaped nozzle geometry to induce the jet stream above the collector inlet (i.e., the region where the IF and CF flows meet), a certain $P$ drop is developed in the system. The IS-PCVI $P\left(P_{\mathrm{CVI}}\right)$ was monitored using a pressure transducer (MKS, 626AX13MDE) installed at the pump outlet line upstream of the mass flow controller, MFC (MFC 1 in Fig. 1). It is noteworthy that we confirm the pressure measured at the pump outlet is identical to the pressure within the PCVI. The $P$ monitoring is important because the fluctuation of $P$ is a good indicator of inappropriate flow development inside the PCVI (e.g., due to the frozen tip of the inlet nozzle). In addition, calibrations of the transducer as well as all $T$ sensors before, during, and after two individual campaigns (INUIT05 and FIN-1) agree within $\pm 1 \%$.

\subsection{Volumetric and mass flow control}

The IS-PCVI operation is automated, such that the various flows are controlled by three MFCs (Fig. 1) and $n$ num- ber of downstream instruments $\left(X_{i}\right)$. Altogether, these external instruments mechanically control pump flow $\left(F_{\mathrm{PF}}\right)$, output flow $\left(F_{\mathrm{OF}}\right)$ and $\mathrm{CF}\left(F_{\mathrm{CF}}\right)$ independently to determine IF $\left(F_{\mathrm{IF}}\right)$. The MFCs are controlled using a LabView instrument control and data acquisition system coupled via FieldPoint $I / O$ modules. Through this integrated system, the set points of the MFCs, i.e., standard mass flows $\left(F_{\mathrm{s}}\right.$ in standard $\mathrm{L} \mathrm{min}^{-1}$ ), are continuously recorded and fed to the LabView interface to adjust individual standard flows to maintain constant actual mass flows $\left(F_{\mathrm{a}}\right.$ in $\left.\mathrm{L} \mathrm{min}^{-1}\right)$ at given $T$ and $P$ in the IS-PCVI system during the experiments. Accordingly, the actual mass flow conditions in the IS-PCVI are expressed as follows:

$$
\begin{aligned}
F_{\mathrm{a}, \mathrm{IF}}\left(\mathrm{Lmin}^{-1}\right) & =F_{\mathrm{a}, \mathrm{PF}}\left(\mathrm{Lmin}^{-1}\right)+F_{\mathrm{a}, \mathrm{OF}}\left(\mathrm{L} \mathrm{min}^{-1}\right) \\
& -F_{\mathrm{a}, \mathrm{CF}}\left(\mathrm{L} \mathrm{min}^{-1}\right),
\end{aligned}
$$

where ECF is determined by subtracting output flow from $\mathrm{CF}\left(F_{\mathrm{a}, \mathrm{ECF}}=F_{\mathrm{a}, \mathrm{CF}}-F_{\mathrm{a}, \mathrm{OF}}\right)$. To hold constant actual mass flows of the MFCs $\left(F_{\mathrm{a}, \mathrm{MFC}} x\right)$, we change the set points of individual flows as follows:

$$
\begin{aligned}
F_{\mathrm{a}, \mathrm{MFC} 1}\left(\mathrm{~L} \mathrm{~min}^{-1}\right) & =F_{\mathrm{s}, \mathrm{PF}}\left(\operatorname{standard~} \mathrm{Lin}^{-1}\right) \\
& \times\left(P_{\mathrm{CVI}} / 1013\right) \times\left(273.15 / T_{\mathrm{CVI}}\right), \\
F_{\mathrm{a}, \mathrm{MFC} 2}\left(\mathrm{~L} \mathrm{~min}^{-1}\right) & =F_{\mathrm{s}, \mathrm{CF}}\left(\operatorname{standard~} \mathrm{min}^{-1}\right) \\
& \times\left(P_{\mathrm{CVI}} / 1013\right) \times\left(273.15 / T_{\mathrm{CVI}}\right), \\
F_{\mathrm{a}, \mathrm{MFC} 3}\left(\mathrm{~L} \mathrm{~min}^{-1}\right) & =\left[F_{\mathrm{s}, \mathrm{OF}}\left(\operatorname{standard~} \min ^{-1}\right)\right. \\
& \left.\times\left(P_{\mathrm{CVI}} / 1013\right) \times\left(273.15 / T_{\mathrm{LAB}}\right)\right] \\
& -\left[F_{\mathrm{s}, \text { total device }}\left(\operatorname{standard~L~min}{ }^{-1}\right)\right. \\
& \left.\times\left(P_{\mathrm{CVI}} / 1013\right) \times\left(273.15 / T_{\mathrm{LAB}}\right)\right],
\end{aligned}
$$

in which the set point of the total device flow $\left(F_{\mathrm{s}, \text { total device }}\right)$ is determined by the summation of the CPC flow $\left(F_{\mathrm{CPC}}\right)$ and the sample flows of downstream device $\left(F_{\mathrm{Xi}}\right)$ :

$$
\begin{gathered}
F_{\mathrm{s}, \text { total device }}\left(\operatorname{standard~} \mathrm{L} \mathrm{min}^{-1}\right)=F_{\mathrm{a}, \mathrm{CPC}}\left(\mathrm{L} \mathrm{min}^{-1}\right) \\
\times\left(1013 / P_{\mathrm{CVI}}\right) \times\left(T_{\mathrm{LAB}} / 273.15\right) \\
+\sum_{i=1}^{n}\left[\begin{array}{c}
\left.F_{\mathrm{s}, \mathrm{Xi}(\operatorname{standard~L~min}}{ }^{-1}\right) \\
\text { or } \\
F_{\mathrm{a}, \mathrm{Xi}\left(\mathrm{L} \mathrm{min}^{-1}\right)} \times\left(\frac{1013}{P_{\mathrm{CVI}}}\right) \times\left(\frac{T_{\mathrm{LAB}}}{273.15}\right)
\end{array}\right] .
\end{gathered}
$$

The principle of the IS-PCVI operation is as follows: (i) an inlet nozzle produces the jet stream of particle-laden air as a downward IF into the system, (ii) an application of upward ECF creates the stagnation regions (i.e., a spot where longitudinal velocity is zero; Kulkarni et al., 2011) in the middle compartment, triggering an inertial separation of cloud particles, (iii) a $\sim 6 \mathrm{~mm}$ thickness cylindrical stainless plate with a total of 12 holes with a $45^{\circ}$ tangential angle builds up a $P$ drop, inducing a uniform outgoing stream of the rejected particles, (iv) a bottom compartment facilitates an incoming $\mathrm{CF}$ 
and an outgoing output flow, which send the cloud elements with high inertia to downstream monitoring instruments, and (v) a pump flow draws the interstitial and low inertia components, which are rejected by the ECF. Consequently, the closed continuous flow system, in which the inflows (sum of sampling IF and CF) are balanced by the external flows (sum of pump flow and output flow), offsets the net flow to be zero. In addition, a total of six custom-made silicon $\mathrm{O}$ rings (Deutsche Hutchinson, SL1008) are used to seal individual compartments and maintain a leak-tight condition. We routinely perform the leak check by filling Helium gas in the IS-PCVI system (sealed by capping the both ends) and detecting leaks throughout the system using a Helium detector. We typically aim at achieving a gas leak rate of less than $10^{-8} \mathrm{~Pa} \mathrm{~s}^{-1}$.

\section{Methodology}

In this section, the CFD simulations (Sect. 3.1), methods in experimental studies (Sect. 3.2) and data analysis method (Sects. 3.3-3.4) are described. In our experiments, inertial particle separation using the IS-PCVI and online residual analyses were simultaneously carried out at various temperatures and supersaturations in the AIDA chamber. The performance of the IS-PCVI was characterized using a series of instruments deployed downstream of the impactor.

\subsection{CFD simulation}

The CFD simulations were performed to evaluate the performance characteristics of the IS-PCVI. The commercially available CFD software FLUENT (ANSYS, Inc.) was employed to perform the three-dimensional simulations to calculate the flow field and various particle size trajectories. The RNG k- $\varepsilon$ turbulence model was employed to account for turbulence effects, and particle trajectories were simulated using Lagrangian discrete phase model. A summary of FLUENT settings pertaining to the simulation on the IS-PCVI model are provided in Table 2.

The GAMBIT software (version 2.4.6) was used to generate the mesh for the CFD solver. Mesh control, such as multi-blocking, was implemented to obtain a better density of the mesh in regions of importance such as where velocity and $P$ change rapidly. A combination of structured and unstructured mesh elements was adapted, and to capture the boundary layer shear flow, a non-dimensional distance, $y^{+}=y \cdot u / v$, was set to approximately unity (ANSYS 14.5). Here, $y$ is the distance from the centroid of the first mesh element from the wall, $u$ is the fraction velocity, and $v$ is the kinematic viscosity. The sensitivity studies with mesh density were performed until the grid-independent CFD results were achieved. Approximately $8 \times 10^{5}$ cells were used and provided a grid-independent solution.
The boundaries of the CFD domain were assigned based on the flow conditions of the IS-PCVI. The boundary condition of "mass flow inlet" was used for the input, output, and add flow boundary zones of the domain, and " $P$ flow inlet" was used for the pump flow boundary zone.

\subsection{Verification of the experimental setup}

We now present our experimental approaches validating the newly developed IS-PCVI. The general layout of our experimental setup at the AIDA facility is illustrated in Fig. 3. In this section, we describe the instrumental techniques employed for the (i) aerosol generation (Sect. 3.2.1), (ii) simulated cloud formation (Sect. 3.2.2), and (iii) in situ residual characterization (Sects. 3.2.3-3.2.7).

\subsubsection{Aerosol generation}

In this study, we utilized a known composition of aerosols from different sources to induce nucleation of ice to generate ice crystals and/or droplets in a controlled manner (summarized in Table S1). As seen in the table, the generation procedure was based on our previous studies. A custom-built atomizer, described in Wex et al. (2015), was used to atomize the ammonium sulfate, sodium chloride, Snomax and PF CGina bacteria suspensions. The suspensions using the first two materials were prepared with a concentration of $0.12 \mathrm{~g}$ solute in $1 \mathrm{~L}$ of $18.2 \mathrm{M} \Omega \mathrm{cm}$ ultrapure water. The Snomax suspension was prepared by suspending $5 \mathrm{~g}$ Snomax in $1 \mathrm{~L}$ of ultrapure water. Likewise, bacteria suspension was suspended in sterile double-distilled water with the optical density $\left(\mathrm{OD}_{600}\right)$ of 1.0 (i.e., the concentration of $\sim 10^{9}$ viable cells $\mathrm{mL}^{-1}$ and a minor contribution of King's Base Agar; personal communication with Kersten Rabe at the Institute for Biological Interfaces, KIT). These seed aerosols were sent through two diffusion dryers (70 mm ID and $253 \mathrm{~mm}$ length each; TOPAS, DDU 570) before injecting into the chamber. Following the procedure introduced in Hiranuma et al. (2014a), the smallscale powder disperser (SSPD, Model 3433, TSI) was used to dry disperse $\sim 1 \mu \mathrm{m}$ diameter hematite particles and inject them into the chamber vessel. Dust particles, including illite $\mathrm{NX}$ and Argentinian soil dust, were generated via the dust disperser (RBG 1000, Palas GmbH) coupled with a series of cyclone impactors $\left(D_{50} \sim 5 \mu \mathrm{m}\right)$. In general, particles were sent into the AIDA chamber vessel as cloud seeds at the beginning of the typical experimental course. An exception was the experiment with a soot injection. For instance, soot particles were added to investigate "unintentional transmission" as they were not expected to activate under the conditions chosen for activation of non-soot INPs. More specifically, a combustion aerosol standard burner (Möhler et al., 2005a) and a spark soot generator (GFG-1000, Palas GmbH, Möhler et al., 2005b; Helsper et al., 1993) were used to directly inject soot into the AIDA vessel during expansion after non-soot- 
Table 2. Summary of the FLUENT settings used for the CFD simulations.

\begin{tabular}{ll}
\hline Solver and solution control & Settings \\
\hline Solver & Three-dimensional double precision, pressure-based Navier Stokes, \\
& $\begin{array}{l}\text { pressure-based, RNG } k \text {-epsilon, steady-state, implicit and absolute velocity } \\
\text { formulation, energy and viscous heating enabled, species transport }\end{array}$ \\
Pressure & Calculation standard \\
Pressure-velocity coupling & SIMPLE \\
Momentum, energy, and turbulent & Second-order upwind \\
\hline
\end{tabular}

derived droplets were fully activated (see Sects. 3.2.7 and 4.8 for more detailed information regarding soot experiments).

\subsubsection{Simulated cloud formation}

The AIDA chamber, consisting of an aluminum cylindershaped vessel of $84 \mathrm{~m}^{3}$ volume in a thermally insulated room housing (Möhler et al., 2003), is used for supercooled cloud formation where aerosols can be activated as droplets and/or ice crystals, forming a variety of simulated clouds (i.e., liquid, mixed-phase or ice clouds). A full description of the AIDA chamber is available in Möhler et al. $(2003,2006)$ with detailed experimental procedures. Hence, only a concise discussion is given in the current manuscript. Briefly, concurrent reduction of the gas $T$ and $P$ in AIDA is achieved by mechanically evacuating air in the chamber (so-called "mechanical expansion"). Pre-injected aerosols in the AIDA vessel are eventually exposed to water and ice supersaturation conditions to be activated as supercooled droplets (typically grown to a few tens of $\mu \mathrm{m}$ ) and/or ice crystals that are distinctly larger than supercooled droplets. During the expansion, the chamber $P$ typically decreases from ambient $P$ to $<800 \mathrm{hPa}$ due to mechanical pumping. Active flow controls based both on the ambient and IS-PCVI conditions (Eqs. 15) maintain the constant $P$ drop in the system and cut size. Downstream instruments were operated with a $P$ controller if it is sensitive to the incoming $P$.

Throughout the experiment, a mixing fan is activated to quickly homogenize air in the chamber. The AIDA gas $T$ is calibrated by comparing a number of $T$ sensors. The resulting $T$ uncertainty is $\pm 0.1 \mathrm{~K}$ (Möhler et al., 2003). A small saturation offset $(+5 \%)$ in the tunable diode laser measurements has been reported in a number of previous AIDA studies (e.g., Hiranuma et al., 2014a). This offset is typically applied for the saturation data to be adjusted onto the theoretical water saturation conditions expected in AIDA during the immersion freezing event. The reason for this systematic offset remains uncertain.

\subsubsection{Transmission efficiency and cut size}

As illustrated in Fig. 3, a combination of four aerosol particle instruments, such as a condensation particle counter (CPC, TSI, Model 3010), a scanning mobility particle sizer (SMPS,
TSI, Model 3080 DMA and Model 3010 CPC), an aerosol particle sizer (APS, TSI, Model 3321), and the white light aerosol spectrometer optical particle counters (welas OPCs, Palas, Sensor series 2300 and 2500; Benz et al., 2005), was used for particle size and number concentration measurements. Specifically, the total number of condensation nuclei $(\mathrm{CN})$ in the AIDA chamber was measured using the CPC 1. The full size distribution of $\mathrm{CN}$ was measured by a combination of the APS and the SMPS before expansion. In addition to the $\mathrm{CN}$ measurement, two OPCs connected to the bottom of the AIDA vessel (OPC 1 and OPC 2) provided the size distributions of cloud particles during the expansion. Both welas OPCs were operated in side-by-side position at individual vertical sampling tubes directly from the bottom vessel of AIDA (upstream of the IS-PCVI) to keep track of temporal evolution of particle size distributions in the chamber during expansion. The detection size ranges (in optical diameters) of the OPC 1 and the OPC 2 complementally corresponded to $0.7-46$ and 5-240 $\mu \mathrm{m})$, respectively. Another welas OPC (OPC 3; Palas, Sensor series 2300) was used behind the IS-PCVI for a limited number of tests. Residual and interstitial particle numbers downstream of the ISPCVI were measured by two individual CPCs (i.e., CPC 2 and CPC 3, respectively). Both CPCs we used were the same model (TSI, Model 3010). Altogether, these instruments provided the spectra of both aerosol and cloud particles.

The particle TE of any CVIs is size-dependent. For example, the potential artifact of the direct impaction of large particles onto the CVI inner wall is reported in a previous study (Chen et al., 2005). As a result, only particles that have sizes around the cut size may be transmitted through the CVI. The transmission of particles larger than $20 \mu \mathrm{m}$ through the NOAA-PCVI tends to decrease according to Fig. 3 in Gallavardin et al. (2008). We test a transmission deficiency in our new IS-PCVI. The test results from INUIT05_29 and_36 are described in Sect. 4.3. In these two expansion experiments, ammonium sulfate was activated in the range of $-10.7^{\circ} \mathrm{C}<T<-5.0{ }^{\circ} \mathrm{C}$.

We now describe a method to optimize the critical cut size, $D_{\text {c }}$, using hydrometeors formed in the AIDA chamber. First, we incrementally sum up the ice and/or droplet number concentrations beginning from the upper bin of the OPC 2 until the summed OPC 2 count becomes equivalent to the num- 
ber of residuals inferred by the CPC 2 (i.e., observed ice crystals and/or droplets $\approx$ residuals). Subsequently, $D_{\mathrm{c}}$ can be optimized as a diameter equivalent to the mid-bin size of the point where INPs and/or CCNs $\approx$ residuals. Using the abovementioned instruments, the cut size of the IS-PCVI is characterized (Sect. 4.4).

\subsubsection{Performance of the evaporation section}

Theoretically, a 5-20 $\mu \mathrm{m} D_{\mathrm{ve}}$ droplet of pure water requires $0.01-0.17 \mathrm{~s}$ to completely evaporate in the outlet where a constant dry air mass flow is maintained at $40^{\circ} \mathrm{C}$ (Chapter 13 of Hinds, 1999). Since the total volume of air in the outlet $(\mathrm{OD} \phi 10 \times 1 \mathrm{~m})$ between the IS-PCVI and the OPC 3 is $\sim 0.08 \mathrm{~L}$, which is much larger than the volume of air transmitted in $0.17 \mathrm{~s}$ at the highest sampling flow we use $(0.017 \mathrm{~L}$ at $\left.6 \mathrm{~L} \mathrm{~min}^{-1}\right)$, it is safe to assume that all condensed phase of water can be vaporized by the time particles reach an OPC 3 downstream of the IS-PCVI.

We conducted a set of two expansion experiments (INUIT05_09 and_12) to examine if the heated tube sections downstream of the IS-PCVI (termed as an evaporation section; see Fig. 3) efficiently evaporates droplets and ice particles. We used $1 \mu \mathrm{m}$ quasi-monodispersed hematite (Hiranuma et al., 2014a) as droplet seeds in a set of two expansion experiments (INUIT05_09 and_12) to verify the performance of the IS-PCVI evaporation section. The droplet onset was recorded by both the AIDA OPC (OPC 1) and the IS-PCVI OPC (OPC 3 ) in the range of $-22^{\circ} \mathrm{C}<T<-15^{\circ} \mathrm{C}$ corresponding to the $P$ reduction from 1000 to $800 \mathrm{hPa}$ in the chamber vessel. The results are presented in Sect. 4.5.

\subsubsection{Test of interstitial particle measurements}

The measurement of rejected particle concentrations in the pump flow (Fig. 1b) was conducted to compare it to the residuals concentration in the sample output flow and the total particle concentration in AIDA. Deploying the CPC 3 in the pump flow line allowed to measure the number concentration of interstitial particles smaller than a $D_{\text {c }}$ cut size of the ISPCVI during three expansion experiments. Ammonium sulfate (INUIT05_34) and sodium chloride (INUIT05_51 and _58) were activated to droplets and ice crystals in these three expansions. Concurrently, the total particle number concentration in AIDA (CPC 1), residual concentration in the output flow (CPC 2) and interstitial particle concentration in the pump flow (CPC 3) were measured. The results are discussed in Sect. 4.6.

\subsubsection{Droplets and ice particle characterization with the PPD-2K}

The Particle Phase Discriminator mark 2, Karlsruhe edition (PPD-2K; University of Hertfordshire, UK; Kaye et al., 2008) is a laser light scattering particle spectrometer that acquires high-resolution spatial light scattering patterns of in- dividual cloud particles in the $7-26^{\circ}$ angular range with respect to the laser propagation direction. The scattering intensities of the sampled particles are analyzed to determine the particle size distribution in the $7-70 \mu \mathrm{m}$ range. In addition, light scattering patterns are acquired for a subsample of the particles with a maximum acquisition rate of $30 \mathrm{~Hz}$. These scattering patterns contain a wealth of microphysical information like phase, shape and small-scale ice crystal complexity. Details on the size calibration as well as phase and shape discrimination can be found in Vochezer et al. (2016). A description of how ice crystal complexity is deduced from high-resolution light scattering patterns is given in Schnaiter et al. (2016).

In this study, the PPD-2K was used to examine the phase of inertially segregated particles and to provide insight into the potential impact of the CVI-driven artifacts (i.e., particle collision, coalescence, shuttering, wake capture effect) onto further downstream measurements. Specifically, coupled with the PPD-2K, a few AIDA expansion measurements were performed to gain insight in the inertially separated droplets and ice particles downstream of the IS-PCVI. We conducted a series of two expansion experiments using $\mathrm{NaCl}$ as seed aerosols. $\mathrm{NaCl}$ particles were activated to droplets followed by homogeneous freezing of ice crystals below $-35^{\circ} \mathrm{C}$ during these expansions. In the first expansion, we tested the IS-PCVI in the non-CF static mode (i.e., the IS-PCVI as a regular outlet) to show the presence of both droplets and ice particles. By contrast, another expansion was carried out by operating the IS-PCVI in the CF mode to let only ice crystals reach to the PPD-2K. All heating components were turned off in INUIT05_55, and only nozzle heating (kept at $-28^{\circ} \mathrm{C}$ ) was employed in INUIT05_56. The results are shown in Sect. 4.7.

\subsubsection{AIDA cloud residual characterization with miniSPLAT}

Next, we describe the methodology to determine the physical properties (e.g., size) and chemical composition of the AIDA cloud residuals and interstitial particles. As described above, sampled air containing high inertia particles is directed vertically and injected into the heating tubes. Subsequently, the output flow is guided to the instruments, such as CPC 2, CPC 3, OPC 3 and miniSPLAT, as illustrated in Fig. 3. The transmitted residual particles are first counted by the OPC 3 at the outlet of the IS-PCVI. The residual number was also counted by directing 1.0 volumetric $\mathrm{L} \mathrm{min}^{-1}$ to the CPC 2 . The rest of downstream instruments connected to the shared outlet allow the characterization of cloud residuals in a continuous stream of residuals at controlled conditions during the experiment.

The composition determination as a function of $T$ and supersaturation in the AIDA chamber was accomplished by utilizing a custom-built single particle mass spectrometer, miniSPLAT. The detailed discussion regarding the instrument's 
performance (e.g., detection efficiency as a function of particle size) is available in Zelenyuk et al. (2015). Coupled with miniSPLAT, the AIDA expansion experiments were conducted to examine the artifacts such as inadvertent intrusion of unwanted interstitial particles and cloud elements within the output flow. One important mechanism through which these artifacts could occur was through wake capture (Pekour and Cziczo., 2011). One expansion experiment (FIN01_38) was designed to examine if intrusion could occur to the ISPCVI outfit using a mixture of soot particles and the other particle type (i.e., bacteria particles, Sect. 4.8) possessing different chemical and ice-nucleating properties.

\subsection{Residual concentration corrections}

To obtain the number concentrations of the IS-PCVI residuals that are comparable with the AIDA droplet and ice particle size distributions $\left(N_{\text {residual }}\right)$, the number concentration of residuals measured downstream of the IS-PCVI $\left(N_{\mathrm{CPC} 2}\right)$ has to be corrected for (i) the calibration factor of the CPCs and (ii) the particle concentration factor:

$N_{\text {residual }}=N_{\mathrm{CPC} 2} \times \frac{\mathrm{CPC}_{\text {upstream }}}{\mathrm{CPC}_{\text {downstream }}} \times \frac{F_{\text {output }}}{F_{\text {input }}}$.

In the typical operation condition of the IS-PCVI, the calibration factor of the $\mathrm{CPCs}\left(\frac{\mathrm{CPC}_{\text {upstream }}}{\mathrm{CPC}_{\text {downstream }}}=\frac{\mathrm{CPC} 1}{\mathrm{CPC} 2}\right)$ is $\sim 1.3$ (i.e., $\sim 25 \%$ particle loss through the IS-PCVI system). Note that the particle loss of the external inlet upstream of the ISPCVI is accounted for in $\frac{\text { CPC } 1}{\text { CPC } 2}$. The time delay of the residual transport in the system (15-20s) is incorporated in the residual number concentration estimation. The IS-PCVI also functions as a particle concentrator with EF up to 20 times, such that the concentrated residuals and particles through the IS-PCVI can be distributed to the downstream monitoring device. The flow concentration factor $\left(\frac{F_{\text {input }}}{F_{\text {output }}}\right)$ is $12.5-$ 28.0. The residual concentrations, which are measured by the CPC 2 and reported in this study, are corrected based on Eq. (6), unless otherwise stated. As discussed below, we neglect the effect of nozzle heating and other artifacts (i.e., Sects. 4.5 and 4.8).

\subsection{Volume-equivalent size of ice crystals}

The welas OPC overestimates actual sizes of non-spherical particles as the estimated size of this OPC represents the particle size inferred by the Mie theory assuming spherical particles of known refractive index (Benz et al., 2005). Since we do not know the physical relation between optical size and actual non-spherical ice size, we estimated the overestimation factor of the OPC $(\Psi)$. Previously, a conversion factor of 0.45 has been applied for converting the optical size of aspherical fibrous particles to their $D_{\text {ve }}$ (Hiranuma et al., 2015). A degree of size overestimation for ice crystal habits is expected to be larger than that for irregularly shaped particles. Conceptually, this factor can be estimated by relating

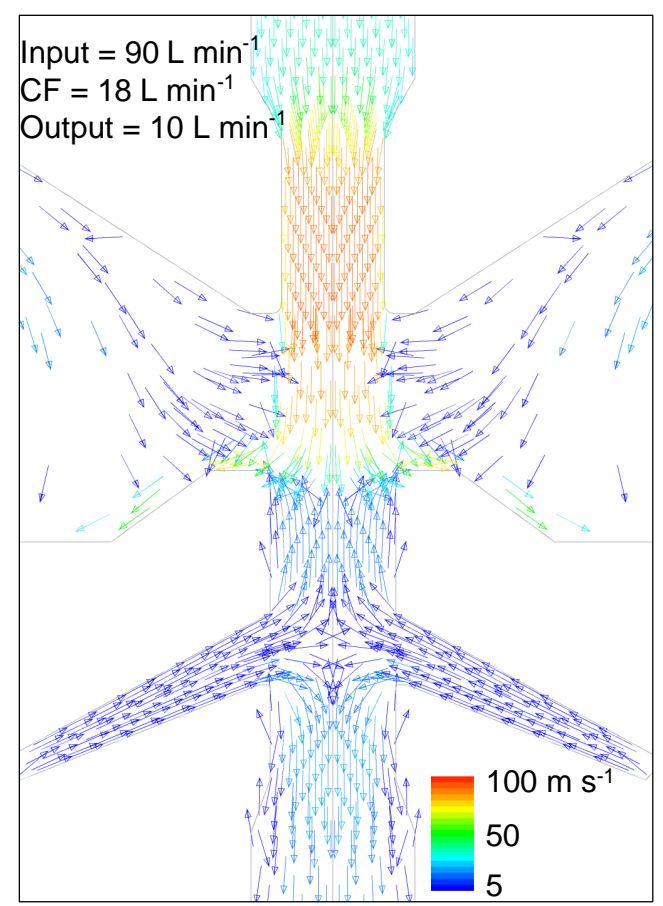

Figure 4. CFD-simulated velocity pathlines. The center region, where the downward and upward velocities meet, coincides with the location of two stagnation planes (the first one at the collector inlet and the second one at the CF outlet) and nozzle jet surface distortion.

the measured time rate change of diffusional growth of ice mass inferred by the OPC measurement $\left(\frac{\mathrm{d} M}{\mathrm{~d} t}\right.$ OPC $)$ to the predicted rate ( $\frac{\mathrm{d} M}{\mathrm{~d} t}$ predicted ;inds, 1999):

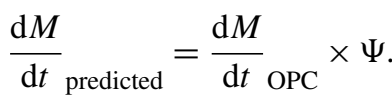

Alternatively, we can also optimize this factor by relating the total condensed water volume ( $\left.V_{\text {optimized }}\right)$, which can be estimated by subtracting the vapor phase water volume $\left(V_{\text {vapor }}\right)$ inferred by in situ tunable diode laser water vapor absorption spectroscopy (Fahey et al., 2014) from the total water content in the chamber $\left(V_{\infty}\right)$ inferred by a fast high precision chilled mirror hygrometer (MBW, model 373; Wagner et al., 2008), to that derived from OPC $\left(V_{\mathrm{OPC}}\right)$ :

$V_{\text {optimized }}=V_{\infty}-V_{\text {vapor }}=V_{\mathrm{OPC}} \times \Psi$.

To verify this notion and to find the conversion factor applied for ice crystals in our AIDA experiments, maximum optical sizes of ice crystals measured by the welas OPC during five expansions (INUIT05_55-59; i.e., homogeneous freezing experiments in $-37.0^{\circ} \mathrm{C}<T<-27.7^{\circ} \mathrm{C}$ with ammonium sulfate $\left(207.1 \mathrm{~cm}^{-3}<\mathrm{CN}\right.$ at $t=0$ $\left.\left(\mathrm{CN}_{0}\right)<238.0 \mathrm{~cm}^{-3}\right)$ ) were compared to the predicted maximum size according to uniform ice growth by water vapor deposition (Hinds, 1999). As expected, we found 


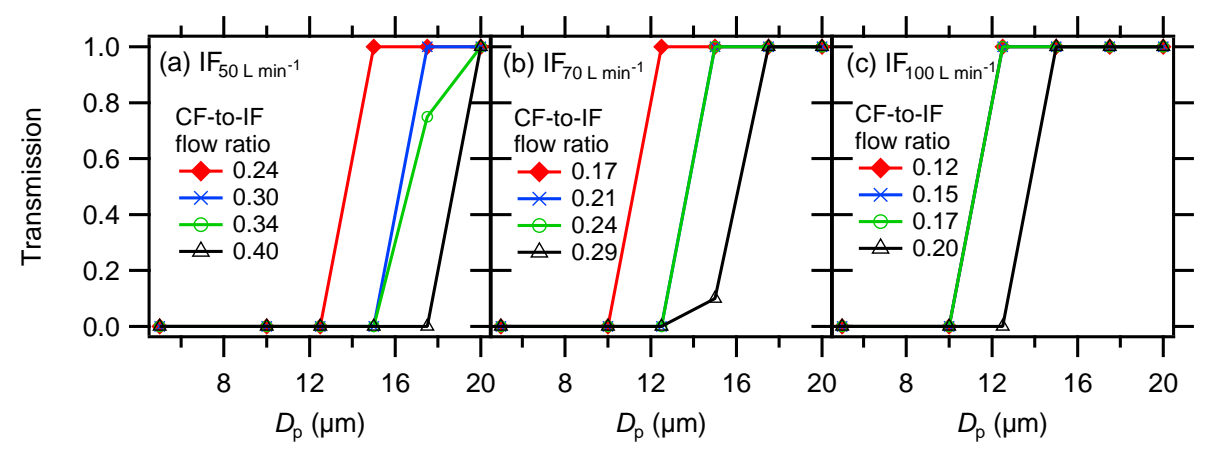

Figure 5. Comparison of the TE calculated from the CFD studies. The results of three different IFs $\left(50,70\right.$ and $\left.100 \mathrm{~L} \mathrm{~min}^{-1}\right)$ with various CF-to-IF flow ratios are shown in panel $(\mathbf{a}, \mathbf{b})$ and $(\mathbf{c})$, respectively. The CFD model simulates particles that are perfectly spherical.

overestimations of ice sizes to be a factor of $\sim 4.2-4.9$ and determined the correction factor of $0.20-0.24$ to convert the welas OPC size to $D_{\text {ve }}$ of ice crystals in this study.

\section{Results and discussion}

The performance validation of the IS-PCVI was carried out at the AIDA facility. The four phases of validation experiment included: (1) CFD simulation study (Sect. 4.1), (2) ice separation, TE and cut-size tests using the AIDA aerosol and cloud particle instruments (Sects. 4.2-4.6), (3) characterization of droplets and ice particles using a combination of AIDA/IS-PCVI/PPD-2K (Sect. 4.7) and (4) physicochemical characterization of test aerosol particles and ice residuals and potential ice fragments using a single particle mass spectrometer (Sect. 4.8).

\subsection{CFD results}

An example of the CFD-simulated velocity pathlines under one condition (IF, CF, output flow $=90,18,10 \mathrm{~L} \mathrm{~min}^{-1}$, respectively) is shown in Fig. 4. It can be observed that velocities within the nozzle are higher than other regions of the IS-PCVI. Two stagnation planes are also observed. The distance between these two planes is the distance that a particle must travel against the CF, such that the longer distance represents the higher inertial barrier (Kulkarni et al., 2011). A comparison of the idealized TE calculated from our CFD studies is shown in Fig. 5. In the CFD study, the TE of spherical particles was calculated by launching $\sim 200$ particles of each different sizes $\left(D_{\mathrm{p}}\right)$ from the IF boundary and taking the ratio of the launched particles to the number of particles that exit the output flow boundary. The trajectories of such injections were computed assuming that they do not impact the flow field, but the flow field is permitted to act on the particles. Comparisons of the CFD simulations to the experimental results are discussed in the next two sections.

\subsection{Ice residual separation}

Figure 6 summarizes an AIDA expansion experiment (FIN01_04) to activate illite NX $\left(\mathrm{CN}_{0}=327 \mathrm{~cm}^{-3}\right.$; mode $\left.D_{\text {ve }}=260 \mathrm{~nm}\right)$ to droplets and ice crystals. Temporal profiles of the chamber mean $T$ and $P$ are presented in panels $\mathrm{a}$ and $\mathrm{b}$, respectively. Simultaneous reduction of the gas $T$ and $P$ in AIDA was achieved by mechanical expansion, resulting in a supersaturation condition both with respect to ice and water (panel c). The number concentration of ice crystals were estimated by summing $>15 \mu \mathrm{m} D_{\text {ve }}$ particles of the welas OPC 2 (panel d). Ice crystal residual concentration after evaporating the water content downstream of the IS-PCVI was quantified by the CPC 2 (panel d). The residual concentrations corrected based on Eq. (6) (i.e., CPC 2 corr. in Fig. 6d) were smaller than the OPC 2 counts (i.e., $>15 \mu \mathrm{m}$ $D_{\text {ve }}$ ) all the time, suggesting that the actual cut size of ice crystals penetrated through the IS-PCVI was much larger than $15 \mu \mathrm{m}$. As expected, the estimate $D_{\mathrm{c}}$ was $\sim 24 \mu \mathrm{m} D_{\text {ve }}$ (panel e). The mass flow conditions in the IS-PCVI were actively controlled based on the AIDA gas $T$ and the IS-PCVI $P$ to maintain constant flow conditions $\left(\mathrm{CF}=9.5 \mathrm{~L} \mathrm{~min}^{-1}\right.$; $\mathrm{IF}=70 \mathrm{~L} \mathrm{~min}^{-1} ; \mathrm{OF}=2.5 \mathrm{~L} \mathrm{~min}^{-1}$ ) for sampling ice crystals $\sim 24 \mu \mathrm{m} D_{\text {ve }}$. During this expansion, the sum of particle concentrations above $15 \mu \mathrm{m} D_{\text {ve }}$ detected by OPC 2 exceeded $0.1 \mathrm{~cm}^{3}$ after 15:26:40 CET. Likewise, the CPC 2 counted $>0.1 \mathrm{~cm}^{3}$ of ice residuals for the same period of the experiment. The average $D_{\mathrm{c}} \pm$ standard deviation was $23.8 \pm 3.0 \mu \mathrm{m}$. This $D_{\mathrm{c}}$ is still larger than the CFD-simulated cut size $(12 \mu \mathrm{m}$; red dotted line in Fig. 6e). A detailed characterization of the IS-PCVI flow conditions of individual AIDA cloud simulation chamber experiments and $D_{\mathrm{c}}$ is summarized in Table S2.

\subsection{Transmission efficiency}

Figure 7 shows the lower-bound TE spectrum (below $10 \mu \mathrm{m}$ ) of the IS-PCVI from INUIT05_29 in comparison to previous measurements with the traditional PCVI. To be comparable to the previous AIDA study, we used a somewhat similar 


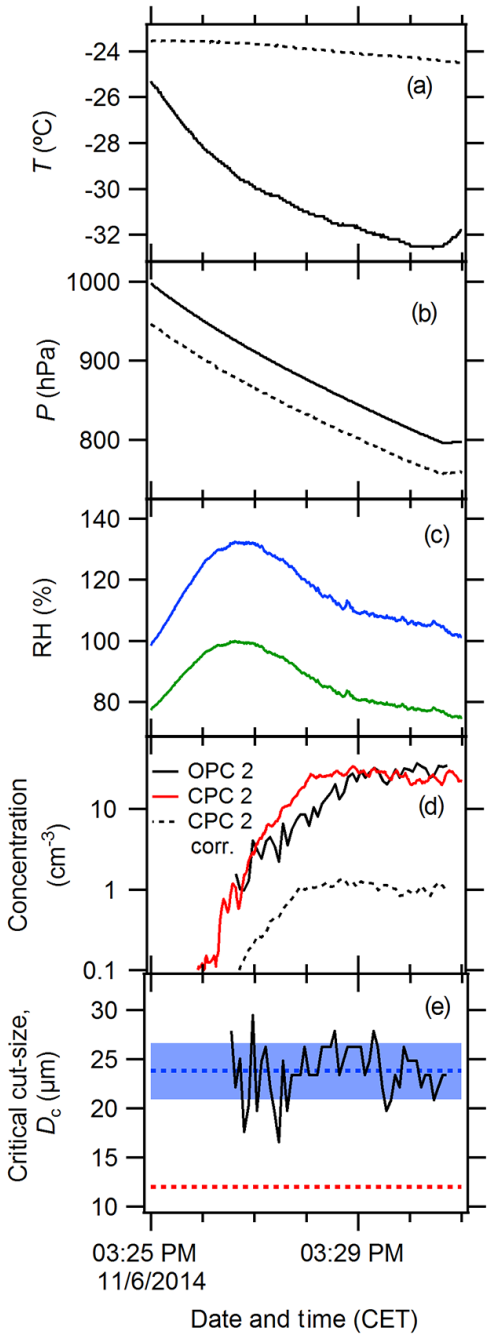

Figure 6. Temporal plots of the AIDA freezing experiment. Arrays of alphabetical panels represent the chamber gas $T$ (solid line) and the IS-PCVI nozzle $T$ (dotted line) (a), $P$ in the AIDA chamber (solid line) and the IS-PCVI (dotted line) (b), RH with respect to water (green line) and ice (blue line) (c), number concentration of $>15 \mu \mathrm{m} D_{\mathrm{ve}}$ AIDA particles measured by the OPC 2 (black solid line), residuals measured by the CPC 2 (red solid line) and corrected residual concentration according to Eq. (6) (black dashed line) (d), and optimized $D_{\mathrm{c}}$ (black line) overlaid on the average $D_{\mathrm{c}}$ (blue dotted line) \pm standard deviation (blue shaded area) (e). The red dotted line in panel (e) represents the cut size predicted by the CFD simulation. RHs were determined with an accuracy of $\pm 5 \%$ using the mean gas temperature and the mean water vapor concentration (Hiranuma et al., 2014b and references therein).

methodology of the TE evaluation described in Gallavardin et al. (2008). Briefly, the TE spectrum of the IS-PCVI was understood by plotting the ratio of droplet residual concentration measured by the CPC 2 after the IS-PCVI to the activated droplet number concentration above its $D_{\mathrm{c}}$ $(15.3 \pm 1.9 \mu \mathrm{m}$; Table S2) as a function droplet diameter in $D_{\text {ve }}$. The only difference between Gallavardin et al. (2008)

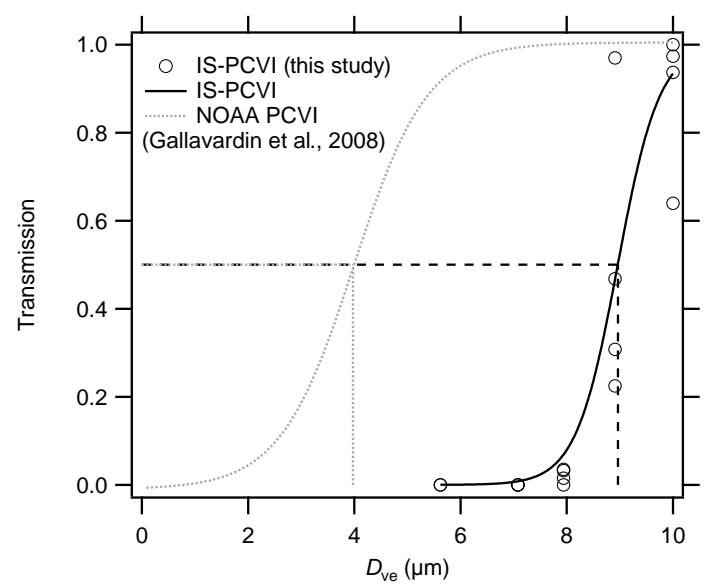

Figure 7. Lower-bound transmission curves of two PCVIs as a function of particle size in $D_{\mathrm{ve}}$. The measurements were carried out with the CF-to-IF ratio 0.1 and $0.3-0.4$ for the ISPCVI (INUIT05_29) and the NOAA-PCVI (IN08_13), respectively. Crossing-points of dot lines represent $50 \%$ cut size.

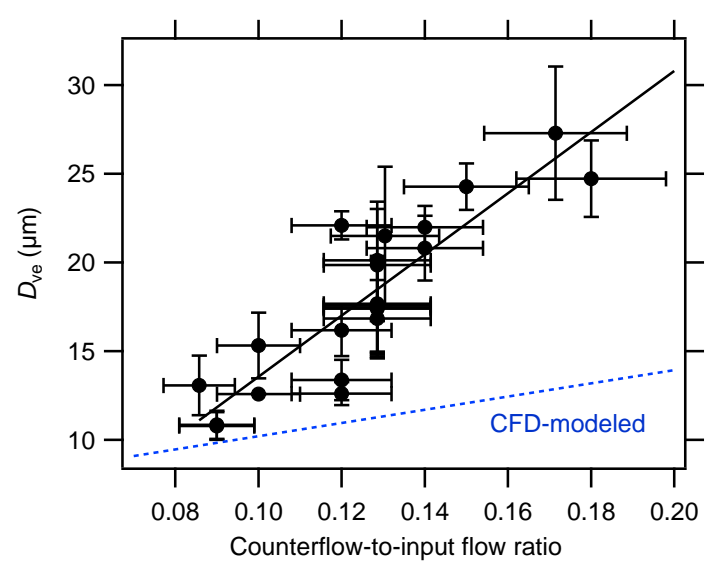

Figure 8. Droplet cut-size spectrum as a function of the CF-to-IF ratio. During our validation tests, we systematically varied the ISPCVI flow conditions (Table S2).

and the current study is the derivation of the droplet diameter. While Gallavardin et al. (2008) used Fourier transform infrared spectroscopy to determine the liquid droplet diameter over the course of the expansion, we used the count median diameters of the AIDA OPCs (i.e., OPC 1 and 2). Despite the difference, we successfully generated supercooled droplets up to $\sim 25 \mu \mathrm{m} D_{\mathrm{ve}}$ in the chamber. The IS-PCVI was operated with $7 \mathrm{~L} \mathrm{~min}^{-1} \mathrm{CF}$ and $70 \mathrm{~L} \mathrm{~min}^{-1} \mathrm{IF}$. For these flow conditions, the estimated $50 \%$ cut size for this particular expansion was $\sim 9 \pm 1 \mu \mathrm{m}$ for the IS-PCVI based on the sigmoidal fits on the calculated transmission spectra $(5 \mathrm{~s}$ time averaged). As shown in Fig. 7, the IS-PCVI separated cloud elements with larger cut size as compared to the traditional one. This unique feature of the IS-PCVI was helpful to sep- 


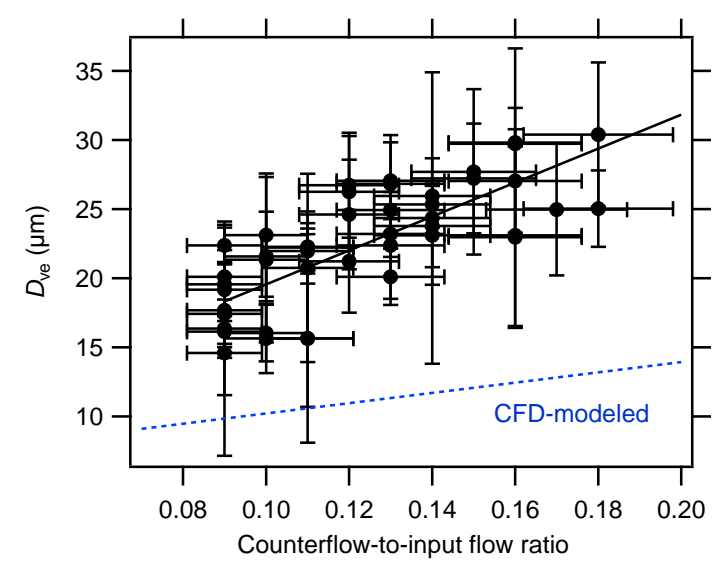

Figure 9. Ice particle cut-size spectrum as a function of the CF-toIF ratio. During our validation tests, we systematically varied the IS-PCVI flow conditions (Table S2).

arate the ice crystals from supercooled droplets, and this operation was not possible with the traditional PCVI.

Additionally, simultaneous measurements of two identical welas OPCs (OPC 1 and OPC 3; Palas, sensor series 2300) were carried out during INUIT05_36. We deployed the welas OPCs before and after the IS-PCVI to estimate the droplet $\mathrm{TE} \sim \frac{\text { Downstream } \mathrm{d} N / \operatorname{dlog} D_{\mathrm{p}}}{\text { Upstream } \mathrm{d} N / \operatorname{dlog} D_{\mathrm{p}}}$ based on the OPC size bins. The PCVI flow concentration factor correction is accounted for the OPC 3 counts. We note that the nozzle heating was kept at $\sim-5{ }^{\circ} \mathrm{C}$ to prevent the nozzle from freezing while the outlet heating was turned off to prevent evaporation of droplets. The results showed that the $50 \%$ TE of the IS-PCVI was approximately $30 \mu \mathrm{m}$. The observed particle losses may have occurred in the external inlet and/or the IS-PCVI. Droplet evaporation due to the dry counterflow may also have played a role. Nevertheless, this TE result was used to optimize the welas OPC size distributions in this study.

\subsection{Cut size of droplets and ice crystals}

The droplet $D_{\mathrm{c}}$ cut-size curve as a function of the ratio of CF-to-IF is shown in Fig. 8. As can be seen in the figure, the IS-PCVI cut size linearly correlates with the CF-to-input ratio (correlation coefficient, $r=0.88$ ). This feature is analogous to the traditional PCVI (Kulkarni et al., 2011). As a caveat, our measurements disagree with the CFD-simulated diameters, presumably due to impaction losses in fittings and small scale flow features such as eddies that are not included in the CFD simulations. Assessing the uncertainty in the CFD analysis is beyond the scope of this paper. Nonetheless, our measurement results show that the cut size is valid only for the specific flow conditions. For instance, the CF-to-IF ratio must be within the range of $0.09-0.18$. The linear relation may not hold if the ratio is outside these bounds. The ratio of CF-to-IF for the traditional PCVI has to be in the range of 0.18-0.4 ( $r=0.71$; Kulkarni et al., 2011). It is also note- worthy that no transmission of supercooled droplets and ice crystals occurs when we apply the set point of cut size greater than the observed droplet size. Rejecting all the particles with high CF-to-IF ratio (>0.4) is verified in 13 expansion tests (INUIT05_1-13 conducted with dry dispersed hematite particles).

Another $D_{\text {c }}$ cut-size curve specifically for pristine ice crystals is shown in Fig. 9. As seen, $D_{\mathrm{c}}$ increases with the CF-to-IF ratio from 0.09 to $0.18(r=0.77)$. Further, similar to the droplet cut-size experiments, our ice crystal test verifies the performance of the IS-PCVI in the $D_{\mathrm{c}}$ range of $\sim 10-30 \mu \mathrm{m}$. The correction factor of $0.20-0.24$ is applied to convert the welas OPC size to $D_{\mathrm{ve}}$ of ice crystals as prescribed in Sect. 3.4.

\subsection{Efficiency of the evaporation section}

The temporal evolution of droplet size distributions measured with the welas OPCs is shown in Fig. 10. In the first experiment, we switched off all the IS-PCVI flows (INUIT05_09). The evaporation section $T$ was maintained at $40^{\circ} \mathrm{C}$ throughout the experiment, while all other heating components were turned off. As expected, the OPC 3 detected negligible signal of droplets (the value of $N>2 \mu \mathrm{m}$ hovering $\sim 0 \mathrm{~cm}^{-3}$ as illustrated in Fig. 10b), showing that the heated line is evaporating the droplets efficiently. After the first experiment, we completely cleaned the AIDA chamber and refilled with dry synthetic air to $\sim 1000 \mathrm{hPa}$ for the following experiment. For the second experiment, the heating of the IS-PCVI outlet was turned off (INUIT05_12). In contrast to the first experiment, the welas OPCs measured almost identical droplet size distributions and similar particle concentrations above $2 \mu \mathrm{m} D_{\text {ve }}$ (not shown). These results verified the proper performance of evaporation section.

\subsection{Characterization of interstitial particles in the pump flow}

Interstitial particle concentrations were measured in the pump flow in INUIT05_34, _51 and _58. The CF-to-IF ratio was maintained to be $0.13,0.13$ and 0.16 for INUIT05_34, _51 and _58, respectively, throughout each experiment. Comparison of the total particle number concentration to the sum of residuals and interstitial particles is illustrated in Fig. 11. This figure shows that the total particle number concentration is in good agreement with the sum of residual concentration and unactivated aerosols. Two important implications of this figure include (1) the separation of interstitial components from cloud elements larger than given $D_{\text {c }}$ cut size is valid and (2) there is negligible loss of interstitial particles in the IS-PCVI. Though the flow dilution or concentration factors $\left(\frac{F_{\text {output }}}{F_{\text {input }}}\right.$ and $\frac{F_{\text {input }}}{F_{\text {pump }}}$ for the CPC 2 and CPC 3, respectively) and the particle losses through CPCs (i.e., $\sim 25 \%$ for the CPC 2 as abovementioned in Sect. 3.3 and $\sim 10 \%$ for the CPC 3 ) are accounted in our CPC counts 

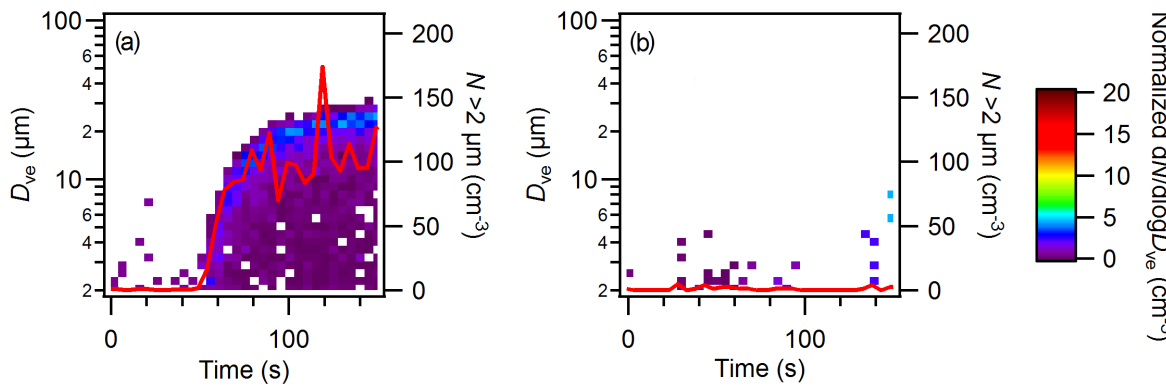

Figure 10. Temporal evolution of droplet size distributions during INUIT05_09. Normalized size distributions of droplets $\left(\mathrm{d} N / \mathrm{d} l o g D_{\mathrm{ve}}\right)$ were derived from the measurements in the chamber (OPC 1) (a) and downstream of the IS-PCVI (OPC 3) (b). Red lines represent the summed particle number above $2 \mu \mathrm{m} D_{\mathrm{ve}}$. The enhancement factor correction was not applied due to the static mode operation of the IS-PCVI.

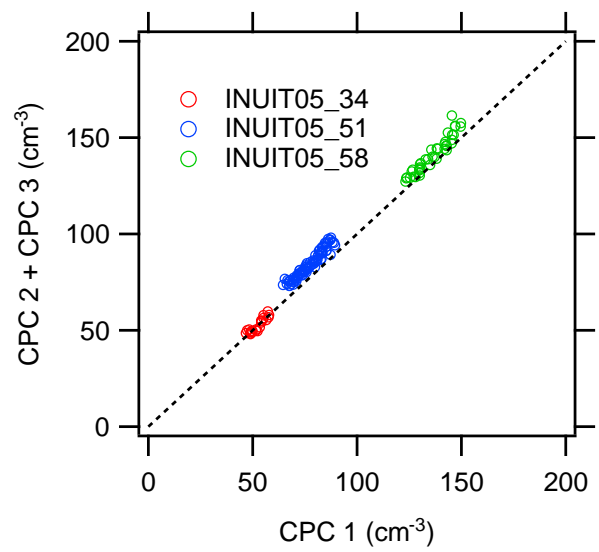

Figure 11. Comparison of the total particle number concentration in AIDA to the sum of residuals in the output flow and interstitial particles in the pump flow. The dashed line represents $1: 1$.

reported in Fig. 11, the concentration accuracy of CPCs in the manufacturer's report $( \pm 10 \%)$ cannot be ruled out as a source of data diversity. Regardless, our observation suggests that the total particle number density measured by the CPC 1 agrees with the sum of residual density in the sample flow (CPC 2) and interstitial aerosols in the pump flow (CPC 3) within $\pm 10 \%$. We note that a maximum of $8 \%$ loss of droplets in the IS-PCVI can occur (i.e., the sum of the CPC 2 and CPC 3 counts $<$ the CPC 1 counts).

\subsection{Characterization of droplets and ice particles}

Figure 12 shows the time series of the AIDA conditions (panels $\mathrm{i}$ and ii), the welas OPC (panel iii) and properties of droplets and ice particles detected by the PPD-2K in two expansion experiments (panels iv). The minor ice peak was observed with the PPD-2K shortly after initiating first expansion (10:57 in Fig. 12a.iv), presumably due to IN of impurity in AIDA in the deposition mode. The background aerosol concentration measured by the CPC 1 in the AIDA chamber prior to expansion was $0.13 \pm 0.03 \mathrm{~cm}^{-3}$ (av- erage \pm standard deviation of $\sim 10 \mathrm{~min}$ ), and the minor deposition mode nucleation was also observed around 10:56 $\left(\sim 0.12 \mathrm{~cm}^{-3}\right)$ before the droplet formation was observed by AIDA OPCs (Fig. 12a.iii). To support this notion, no deposition IN prior to droplet formation was observed and recorded by both the welas OPC and the PPD-2K in the second subsequent experiment (INUIT05_56). We cannot rule out the possibility of an artifact produced due to local adiabatic expansion at the IS-PCVI acceleration nozzle when CF is switched off. Nonetheless, the impact of nozzle expansion seems negligible. More importantly, the capability of droplet/ice separation in AIDA is shown in Fig. 12b. Target cut size during INUIT05_56 was set to be $20 \mu \mathrm{m}$ for ice extraction. Ice crystal separation was successful as the PPD-2K phase is nearly $100 \%$ ice throughout the expansion (Fig. 12b.iv).

In addition, $D_{\text {ve }}$ of ice crystals upstream and downstream of the IS-PCVI is shown in Fig. 13. As apparent in Fig. 13a, both the welas OPCs (upstream measurement) and the PPD$2 \mathrm{~K}$ (downstream one) clearly showed the presence of small crystals even in a fully glaciated cloud and their dominance in the number size distribution. During this experiment, the PPD-2K measured fewer large ice crystals presumably due to the loss in the sampling line between the IS-PCVI and the PPD-2K. In contrast, ice particles smaller than $20 \mu \mathrm{m}$ $D_{\text {ve }}$ were only detected in the welas OPCs, but a majority of $<20 \mu \mathrm{m}$ ice particles was not measured by the PPD$2 \mathrm{~K}$ instrument in subsequent expansion, verifying the performance of the IS-PCVI to reject interstitial particles. Such iceselective capability represents the uniqueness and usefulness of the IS-PCVI method. It is noteworthy that the ratio of the PPD-2K to the welas OPCs' counts (sigmoidal fit in Fig. 13c) implies $\sim 5 \%$ unintentional transmission of interstitial particles below $10 \mu \mathrm{m} D_{\text {ve }}$. More discussion with respect to the artifact is given in the following section.

\subsection{Artifact characterization}

The results of AIDA experiments to test inadvertent intrusion of unwanted particles are presented below. The time se- 

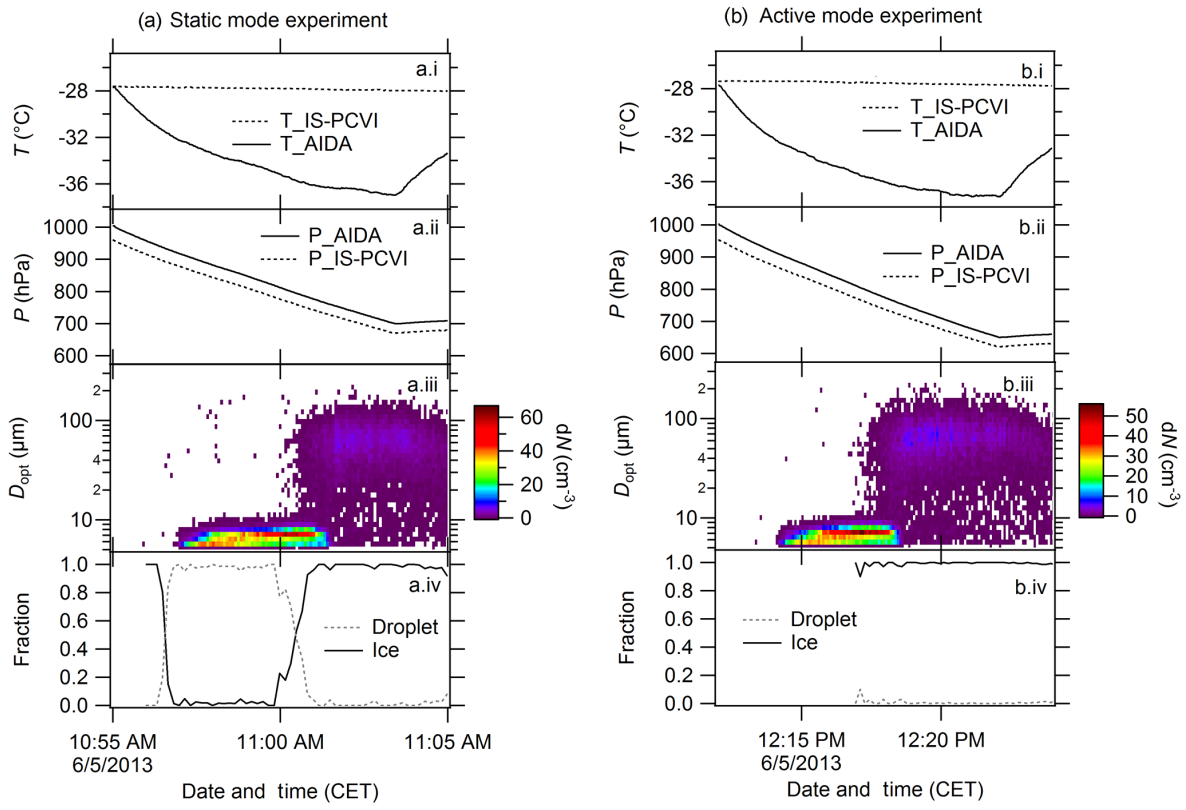

Figure 12. Temporal profiles of the static IS-PCVI/PPD-2K coupling experiment (INUIT05_55) (a) and the active IS-PCVI/PPD-2K coupling one (INUIT05_56) (b). While the IS-PCVI behaves as a regular outlet without any flows in the static mode experiment (a), all flows and MFCs are activated during the active mode experiment (b). Panels are coordinate to display $T$ (i), $P$ (ii), the welas OPC size distribution of droplets and ice crystals in optical diameter $\left(D_{\text {opt }}\right)$ during individual expansions (iii), and the PPD-2K-detected droplets and ice particles fraction (iv). The color scale in panels iii represents the binned-number concentration of particles $(\mathrm{d} N)$.

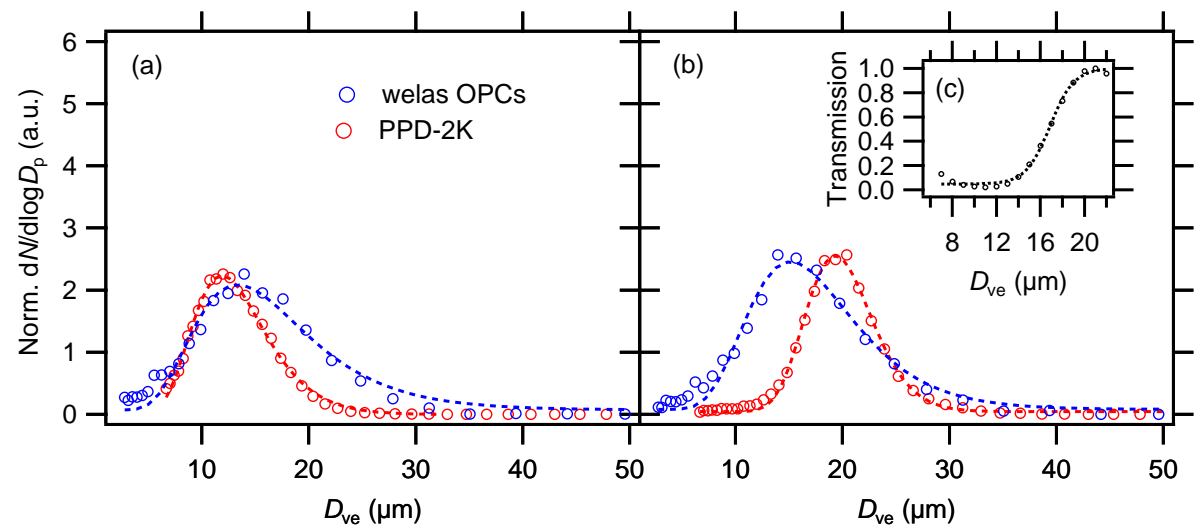

Figure 13. Normalized size distribution of ice particles for INUIT05_55 (static mode) (a) and INUIT05_56 (CF mode)) (b). Size distributions were measured at two locations: the welas OPCs in the chamber and the PPD-2K after the IS-PCVI. $\mathrm{d} N / \mathrm{d} \log D_{\mathrm{p}}$ normalized to the total number concentration measured in each instrument is plotted as a function of ice particles in $D_{\mathrm{ve}}$. The size correction factor of 4.5 was applied to the welas OPC (see text for more details). The PPD-2K size distribution was normalized to the same maximum of the welas OPC size distribution. Both panels a and $b$ represent a snapshot picture of 1 min average size distribution with sufficient amount of ice crystals observed in AIDA [11:01:15-11:02:15 ) (a) and 12:21:15-12:22:15 (b); see also Figs. 12a.iii and 12b.iii]. Subpanel c shows the transmission of ice particles (i.e., particle number ratio of the PPD-2K to the welas OPC scaled up to 1.0) and associated sigmoidal fit.

ries plots of the AIDA experimental trajectories and residual counts downstream of the IS-PCVI are illustrated in Fig. 14.

In the FIN01_38 experiment, atomized bacteria particles (PF CGina bacteria; $\mathrm{CN}_{0}=1415.6 \mathrm{~cm}^{-3}$; mode $D_{\text {ve }}=85 \mathrm{~nm}$ ) were activated in AIDA in the $T$ range of $-12{ }^{\circ} \mathrm{C}<T<-4{ }^{\circ} \mathrm{C}$ (Fig. 14a). Simultaneous $P$ reduction from 1000 to $700 \mathrm{hPa}$ (Fig. 14b) resulted in super- saturation both with respect to ice and water $( \pm 5 \%$; Fig $15 \mathrm{c})$ and immersion freezing of bacteria particles. The miniSPLAT instrument was operated behind the IS-PCVI $\left(\mathrm{CF}=11 \mathrm{~L} \mathrm{~min}^{-1} ; \mathrm{CF}\right.$-to-IF $\left.=0.14\right)$. We injected the GSG soot twice in the middle of this expansion experiment. Soot particles were chosen because they were not activated under these conditions $\left(-12^{\circ} \mathrm{C}<T<-4^{\circ} \mathrm{C}\right)$. Presumably then, 


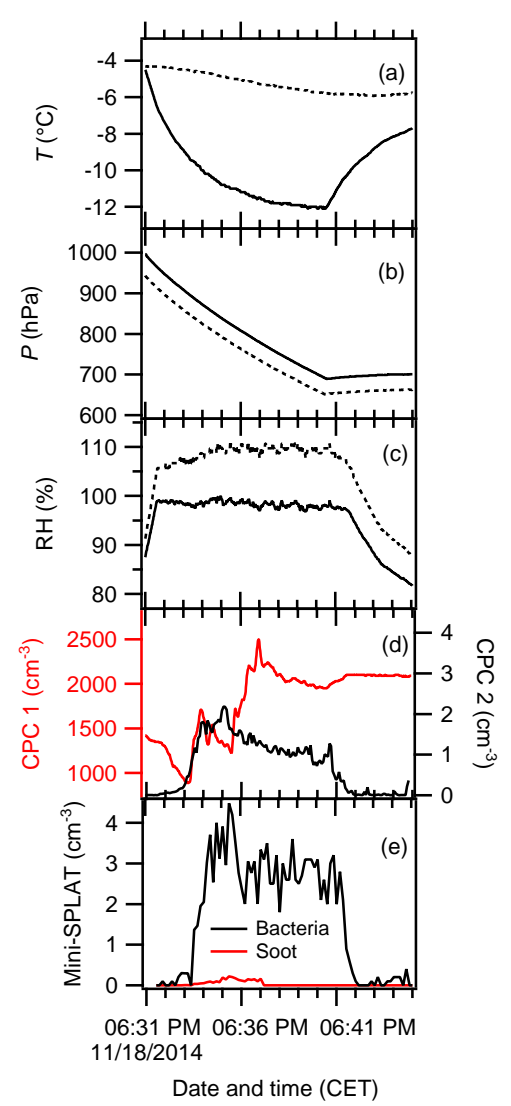

Figure 14. Temporal plots of the AIDA expansion experiments from FIN01_38. Panels are arranged to show the chamber gas $T$ (solid line) and the IS-PCVI nozzle $T$ (dotted line) (a), $P$ in the AIDA chamber (solid line) and the IS-PCVI (dotted line) (b), $\mathrm{RH}$ with respect to water (solid line) and ice (dotted line) (c), CPC counts (left axis $=$ total particle counts from the CPC 1; right axis $=$ residual counts from the CPC 2) (d), and miniSPLATmeasured composition-resolved particle concentration in $\mathrm{cm}^{-3}(\mathbf{e})$. RHs were determined with an accuracy of $\pm 5 \%$. The residual counts measured by CPC 2 are corrected according to Eq. (6), while no enhancement factor correction is included for miniSPLAT concentration.

soot particles that were detected after the IS-PCVI were due to artifacts. The CPC 1 indicated the abrupt increases in particle concentration due to two separate soot injections $\left(>1000 \mathrm{~cm}^{-3}\right.$; Fig. 14d). Figure $14 \mathrm{~d}$ also plots number concentration of the CPC 2, monitoring the number concentration of AIDA cloud residuals. Such residual measurement was carried out throughout expansion, resulting in a total of $>4 \mathrm{~cm}^{-3}$ residual counts in the flow after the IS-PCVI. Two AIDA OPCs showed that cloud droplets grew up to $30 \mu \mathrm{m}$ at liquid saturation, while the critical cut size of the IS-PCVI was set at $\sim 25 \mu \mathrm{m}$. Hence, both droplet and ice residuals were transmitted to miniSPLAT. The rising edge of the CPC 2 occurs at the same point in time as ice crystal formation during the expansion, but there is no corresponding increase in the CPC 2 with the second injection of soot. Evidently, these fresh soot particles remained in interstitial size $\left(<100 \mathrm{~nm} D_{\mathrm{ve}}\right)$, as they did not appear in the welas OPC measurements (not shown), and were not relevant to IN in given $T$ range (Möhler et al., 2005a). The results shown in Fig. 14e indicate that the rising edge observed with miniSPLAT as well as the CPC 2 largely correlates to bacteria with only a small amount of soot $(<5 \%)$ making it through the IS-PCVI. These residual observations support the predominance of non-soot components in cloud residuals and, thereby, validate the performance of inertial separation without much inadvertent intrusion.

\section{Summary}

The main goal of this study is to develop a new PCVI device to separate ice crystals from mixed-phase clouds. The existing traditional PCVI only allows separation of cloud elements with the upper bound cut-size diameter $\sim 5 \mu \mathrm{m}$, such that achieving an efficient extraction of ice crystals alone is a challenge especially in the scenario that droplets that are typically grown to $\geq 10 \mu \mathrm{m}$ coexist with ice crystals that vary in size up to $50 \mu \mathrm{m}$. The new size-selecting inlet, termed IS-PCVI, separates ice particles, which are normally larger, from the others based on the inertial separation.

Prior to device fabrication, we conducted the CFD analysis. The CFD study guided us to optimize the design and helped to understand the performance characteristics of the IS-PCVI across a wide range of experimental parameters. Various design improvements to minimize the impact of artifacts and associated particle losses in the system based on the previous study were also incorporated. After the CFD study, we verified the performance characteristics of the IS-PCVI in the laboratory setting. A sequential experiment involving cloud formation, generation of cloud elements such as supercooled droplets and ice crystals, inertial separation, and residual analyses were carried out as a function of $T$ and supersaturation in the AIDA chamber to test the TE and associated cut size. The AIDA cloud residuals were obtained after the IS-PCVI by stripping off the water content of ice crystals and supercooled droplets through the heated stainless steel tube surrounded by layers of $T$-controlled heating tapes with insulation coverage. Subsequently, the residual-laden air was transported to a series of downstream instruments to examine the operational performance of the IS-PCVI.

The results from a series of experimental validation tests verified the inertial separation of pristine ice crystals of cut size $D_{\text {ve }} \geq>10 \mu \mathrm{m}$. We observed that the IS-PCVI is efficient when the CF-to-IF ratio is in the range of 0.09-0.18. The new device also permits to sample interstitial particles or particles smaller than the wide cut size. Further, the measurements of multiple, complex, analytical instruments were performed downstream of the IS-PCVI. The PPD-2K was deployed downstream of the IS-PCVI to characterize droplets and ice particles transmitted through the IS-PCVI. Using 
the PPD-2K, we also verified the separation of ice particles from droplets and interstitial particles in the AIDAsimulated mixed-phase cloud. The chemical compositions of ice residual particles are analyzed with a single particle mass spectrometer. Within our experimental conditions used in this study, small influences of artifacts $(\sim 5 \%)$ were confirmed by performing physico-chemical characterization of ice residuals downstream of the AIDA chamber using a single particle mass spectrometer.

Overall, the newly developed IS-PCVI complements the current version of the PCVI by providing an additional capability of large ice residual extraction to elucidate the properties of ice residuals and INPs in mixed-phase clouds. The application of the IS-PCVI to characterize ice crystal residuals can enhance the ongoing INP measurements, and such studies would further guide future IN studies towards a better understanding of INPs.

\section{Data availability}

Aerosol types and associated particle generators used in this work are summarized as part of the Supplement. Detailed characteristics of IS-PCVI properties during INUIT05 and FIN01 campaigns are also summarized as supplements. Other information regarding particle properties (i.e., concentration and size distribution of aerosol, droplets, and/or ice) before and during individual AIDA expansion experiments is available upon request. Temporal profiles of the AIDA cloud simulation experiments (as illustrated in Fig. 6) can also be provided.

\section{The Supplement related to this article is available online at doi:10.5194/amt-9-3817-2016-supplement.}

Author contributions. N. Hiranuma and O. Möhler oversaw the deployment and operation of instruments in AIDA, led the data analysis and prepared the manuscript, with input from all authors. GK set up, ran and compiled the CFD studies of the IS-PCVI with support of N. Hiranuma. S. Vogt and N. Hiranuma designed and developed the IS-PCVI equipment with contributions from G. Kulkarni, D. J. Cziczo, R. Wagner and engineers at IMK-AAF. E. Järvinen, P. Vochezer, and M. Schnaiter operated the PPD-2K at AIDA during INUIT05 and provided analysis and interpretation of the PPD-2K data. D. M. Bell, J. Wilson, and A. Zelenyuk operated miniSPLAT at AIDA during FIN-1 and provided analysis and interpretation of miniSPLAT data. The INUIT05 campaign was led by N. Hiranuma and O. Möhler. The FIN-1 activity was coordinated by O. Möhler and D. J. Cziczo with assistance of N. Hiranuma.
Acknowledgements. We thank the Engineering and Infrastructure group at KIT IMK-AAF (Georg Scheurig, Tomasz Chudy and Rainer Buschbacher) for their support in constructing and operating the IS-PCVI. This work was funded by the Helmholtz Association through its research programme "Atmosphere and Climate (ATMO)" and the Deutsche Forschungsgemeinschaft (DFG) through the Research Unit FOR 1525 (INUIT, grant No MO668/4-1 and MO668/4-2). The valuable contributions of the FIN organizers, their institutions, and the FIN-1 Workshop science team are gratefully acknowledged. N. Hiranuma thanks A. Kiselev (KIT IMK-AAF) and K. Rabe (KIT IBG) for their support on the bacteria sample preparation. M. Schnaiter acknowledges the funding by DFG under grant SCHN 1140/2-1. The participation of G. Kulkarni, D. M. Bell, J. Wilson, A. Zelenyuk, and D. J. Cziczo was partially funded by NSF grant\#AGS-1461305. Additional support (A. Zelenyuk, D. M. Bell, J. Wilson, and G. Kulkarni) was provided by the US Department of Energy (DOE) Office of Biological and Environmental Research (OBER) Atmospheric Research Systems Program (ASR). The development of miniSPLAT was funded by the DOE Office of Science, Office of Basic Energy Sciences, Division of Chemical Sciences, Geosciences and Biosciences and EMSL User Facility sponsored by the DOE OBER and located at Pacific Northwest National Laboratory. G. Kulkarni acknowledges support from the US DOE ASR. The Pacific Northwest National Laboratory is operated for DOE by Battelle Memorial Institute under contract DE-AC05-76RLO 1830.

The article processing charges for this open-access

publication were covered by a Research

Centre of the Helmholtz Association.

Edited by: B. Ervens

Reviewed by: two anonymous referees

\section{References}

Anderson, T. L., Charlson, R. J., and Covert, D. S.: Calibration of a counterflow virtual impactor at aerodynamic diameters from 1 to 15 micrometers, Aerosol Sci. Tech., 19, 317-329, doi:10.1080/02786829308959639, 1993.

Benz, S., Megahed, K., Möhler, O., Saathoff, H., Wagner, R., and Schurath, U.: T-dependent rate measurements of homogeneous ice nucleation in cloud droplets using a large atmospheric simulation chamber, J. Photochem. Photobiol. A, 176, 208-217, doi:10.1016/j.jphotochem.2005.08.026, 2005.

Berg, L. K., Berkowitz, C. M., Ogren, J. A., Hostetler, C. A., Ferrare, R. A., Dubey, M. K., Andrews, E., Coulter, R. L., Hair, J. W., Hubbe, J. M., Lee, Y. N., Mazzoleni, C., Olfert, J., and Springston, S. R.: Overview of the Cumulus Humilis Aerosol Processing Study, B. Am. Meteorol. Soc., 90, 16531667, doi:10.1175/2009BAMS2760.1, 2009.

Boucher, O., Randall, D., Artaxo, P., Bretherton, C., Feingold, G., Forster, P., Kerminen, V. M., Kondo, Y., Liao, H., Lohmann, U., Rasch, P., Satheesh, S. K., Sherwood, S., Stevens, B., and Zhang, X. Y.: Clouds and Aerosols. In: Climate Change 2013: The Physical Science Basis. Contribution of Working Group I to the Fifth Assessment Report of the Intergovernmental Panel on Climate Change, edited by: Stocker, T. F., Qin, D., Plattner, G. K., Tig- 
nor, M., Allen, S. K., Boschung, J., Nauels, A., Xia, Y., Bex, V., and Midgley, P. M., Cambridge University Press, Cambridge, UK and New York, NY, USA, 571-657, 2013.

Boulter, J. E., Cziczo, D. J., Middlebrook, A. M., Thomson, D. S., and Murphy, D. M.: Design and performance of a pumped counterflow virtual impactor, Aerosol. Sci. Technol., 40, 969-976, doi:10.1080/02786820600840984, 2006.

Chen, J., Conant, W. C., Rissman, T. A., Flagan, R. C., and Seinfeld, J. H.: Effect of angle of attack on the performance of an airborne counterflow virtual impactor, Aerosol Sci. Tech., 39, 485-491, doi:10.1080/027868290964838, 2005.

China, S., Kulkarni, G., Scarnatio, B., Sharma, N., Pekour, M. S., Shilling, J. E., Wilson, J. M., Zelenyuk, A., Chand, D., Liu, S., Aiken, A., Dubey, M. K., Laskin, A., Zaveri, E. A., and Mazzoleni, C.: Morphology of diesel soot residuals from supercooled water droplets and ice crystals: implications for optical properties, Environ. Res. Lett. 10, 114010, doi:10.1088/17489326/10/11/114010, 2015.

Corbin, J., Rehbein, P., Evans, G., and Abbatt, J.: Combustion particles as ice nuclei in an urban environment: evidence from single particle mass spectrometry, Atmos. Environ., 51, 286-292, doi:10.1016/j.atmosenv.2012.01.007, 2012.

Crawford, I., Möhler, O., Schnaiter, M., Saathoff, H., Liu, D., McMeeking, G., Linke, C., Flynn, M., Bower, K. N., Connolly, P. J., Gallagher, M. W., and Coe, H.: Studies of propane flame soot acting as heterogeneous ice nuclei in conjunction with single particle soot photometer measurements, Atmos. Chem. Phys., 11, 9549-9561, doi:10.5194/acp-11-9549-2011, 2011.

Crumeyrolle, S., Weigel, R., Sellegri, K., Roberts, G., Gomes, L., Stohl, A., Laj, P., Momboisse, G., Bourianne, T., Puygrenier, V., Burnet, F., Chosson, F., Brenguier, J. L., Etcheberry, J. M., Villani, P., Pichon, J. M., and Schwarzenböck, A.: Airborne investigation of the aerosolsecloud interactions in the vicinity and within a marine stratocumulus over the North Sea during EUCAARI (2008), Atmos. Environ., 81, 288-303, doi:10.1016/j.atmosenv.2013.08.035, 2013.

Cziczo, D. J. and Froyd, K. D.: Sampling the composition of cirrus ice residuals, Atmos. Res., 142, 15-31, doi:10.1016/j.atmosres.2013.06.012, 2014.

Cziczo, D. J., DeMott, P. J. Brock, C., Hudson, P. K., Jesse, B., Kreidenweiss, S. M., Prenni, A. J., Schreiner, J., Thomson, D. S., and Murphy, D. M.: A method for single particle mass spectrometry of ice nuclei, Aerosol Sci. Tech., 37, 460-470, doi:10.1080/02786820300976, 2003.

Cziczo, D. J., Stetzer, O., Worringen, A., Ebert, M., Weinbruch, S., Kamphus, M., Gallavardin, S. J., Curtius, J., Borrmann, S., Froyd, K. D., Mertes, S., Möhler, O., and Lohmann, U.: Inadvertent climate modification due to anthropogenic lead, Nat. Geosci., 2, 333-336, doi:101038/NGEO499, 2009.

De Bock, L. A., Joos, P. E., Noone, K. J., Pockalny, R. A., and Van Grieken, R. E.: Single particle analysis of aerosols, observed in the marine boundary layer during the Monterey Area Ship Tracks Experiment (MAST), with respect to cloud droplet formation, J. Atmos. Chem., 37, 299-329, doi:10.1023/A:1006416600722, 2000

DeMott, P. J., Cziczo, D. J., Prenni, A. J., Murphy, D. M., Kreidenweis, S. M., Thomson, D. S., Borys, R., and Rogers, D. C.: Measurements of the concentration and composition of nuclei for cirrus formation, Proc. Natl. Acad. Sci., 100, 14655-14660, doi:10.1073/pnas.2532677100, 2003.

DeMott, P. J., Prenni, A. J., Liu, X., Kreidenweis, S. M., Petters, M. D., Twohy, C. H., Richardson, M. S., Eidhammer, T., and Rodgers, D. C.: Predicting global atmospheric ice nuclei distributions and their impacts on climate, P. Natl. Acad. Sci. USA, 107, 11217-11222, doi:10.1073/pnas.0910818107, 2010.

Després, V. R., Huffman, J. A., Burrows, S. M., Hoose, C., Safatov, A. S., Buryak, G. A., Fröhlich-Nowoisky, J., Elbert, W., Andreae, M. O., Pöschl, U., and Jaenicke, R.: Primary Biological Aerosol Particles in the atmosphere: a review, Tellus B, 64, 15598, doi:10.3402/tellusb.v64i0.15598, 2012.

Fahey, D. W., Gao, R.-S., Möhler, O., Saathoff, H., Schiller, C., Ebert, V., Krämer, M., Peter, T., Amarouche, N., Avallone, L. M., Bauer, R., Bozóki, Z., Christensen, L. E., Davis, S. M., Durry, G., Dyroff, C., Herman, R. L., Hunsmann, S., Khaykin, S. M., Mackrodt, P., Meyer, J., Smith, J. B., Spelten, N., Troy, R. F., Vömel, H., Wagner, S., and Wienhold, F. G.: The AquaVIT-1 intercomparison of atmospheric water vapor measurement techniques, Atmos. Meas. Tech., 7, 3177-3213, doi:10.5194/amt-7-3177-2014, 2014.

Gallavardin, S. J., Froyd, K. D., Lohmann, U., Möhler, O., Murphy, D. M., and Cziczo, D. J.: Single particle laser mass spectrometry applied to differential ice nucleation experiments at the AIDA chamber, Aerosol Sci. Tech., 42, 773-791, doi:10.1080/02786820802339538, 2008.

Gieray, R., Wieser, P., Engelhardt, T., Swietlicki, E., Hansson, H. C., Mentes, B., Orsini, D., Martinsson, B., Svenningsson, B., Noone, K. J., and Heintzenberg, J.: Phase partitioning of aerosol constituents in cloud based on single-particle and bulk analysis, Atmos. Environ., 31, 2491-2502, doi:10.1016/S13522310(96)00298-1, 1997.

Hayden, K. L., Macdonald, A. M., Gong, W., Toom-Sauntry, D., Anlauf, K. G., Leithead, A., Li, S.-M., Leaitch, W. R., and Noone, K.: Cloud processing of nitrate, J. Geophys. Res., 113, D18201, doi:10.1029/2007JD009732, 2008.

Helsper, C., Molter, W., Löffler, F., Wadenpohl, C., and Kaufmann, S.: Investigation of a new aerosol generator for the production of carbon aggregate particles, Atmos. Environ., 27A, 1271-1275, doi:10.1016/0960-1686(93)90254-V, 1993.

Heymsfield, A. J., Miloshevich, L. M., Schmitt, C., Bansemer, A., Twohy, C. Poellot, M. R., Fridland, A., and Gerber, H.: Homogeneous ice nucleation in tropical convection and its influence on cirrus anvil microphysics, J. Atmos. Sci, 62, 41-64, doi:10.1175/JAS-3360.1, 2005.

Hinds, W. C.: Aerosol Technology: Properties, Behavior, and Measurement of Airborne Particles, 2nd Edition, Wiley-Interscience, New York, NY, USA, 278-303, 1999.

Hiranuma, N., Kohn, M., Pekour, M. S., Nelson, D. A., Shilling, J. E., and Cziczo, D. J.: Droplet activation, separation, and compositional analysis: laboratory studies and atmospheric measurements, Atmos. Meas. Tech., 4, 2333-2343, doi:10.5194/amt-42333-2011, 2011.

Hiranuma, N., Brooks, S. D., Moffet, R., Glen, A., Laskin, A., Gilles, M. K., Liu, P., MacDonald, M. A., Strapp, W., and McFarquhar, G. M.: Chemical characterization of individual particles and residuals of cloud droplets and ice crystals collected on board research aircraft in the ISDAC 2008 study, J. Geophys. Res., 118, 6564-6579, doi:10.1002/jgrd.50484, 2013. 
Hiranuma, N., Hoffmann, N., Kiselev, A., Dreyer, A., Zhang, K., Kulkarni, G., Koop, T., and Möhler, O.: Influence of surface morphology on the immersion mode ice nucleation efficiency of hematite particles, Atmos. Chem. Phys., 14, 2315-2324, doi:10.5194/acp-14-2315-2014, 2014a.

Hiranuma, N., Paukert, M., Steinke, I., Zhang, K., Kulkarni, G., Hoose, C., Schnaiter, M., Saathoff, H., and Möhler, O.: A comprehensive parameterization of heterogeneous ice nucleation of dust surrogate: laboratory study with hematite particles and its application to atmospheric models, Atmos. Chem. Phys., 14, 13145-13158, doi:10.5194/acp-14-13145-2014, 2014 b.

Hiranuma, N., Möhler, O., Yamashita, K., Tajiri, T., Saito, A., Kiselev, A., Hoffmann, N., Hoose, C., Jantsch, E., Koop T., and Murakami, M.: Ice nucleation by cellulose and its potential contribution to ice formation in clouds, Nat. Geosci., 8, 273-277, doi:10.1038/ngeo2374, 2015.

Hoose, C. and Möhler, O.: Heterogeneous ice nucleation on atmospheric aerosols: a review of results from laboratory experiments, Atmos. Chem. Phys., 12, 9817-9854, doi:10.5194/acp-12-98172012, 2012.

Hopkins, R. J., Desyaterik, Y., Tivanski, A. V., Zaveri, R. A., Berkowitz, C. M., Tyliszczak, T., Gilles, M. K., and Laskin, A.: Chemical speciation of sulfur in marine cloud droplets and particles: Analysis of individual particles from the marine boundary layer over the California current, J. Geophys. Res., 113, D04209, doi:10.1029/2007JD008954, 2008.

Huffman, J. A., Prenni, A. J., DeMott, P. J., Pöhlker, C., Mason, R. H., Robinson, N. H., Fröhlich-Nowoisky, J., Tobo, Y., Després, V. R., Garcia, E., Gochis, D. J., Harris, E., Müller-Germann, I., Ruzene, C., Schmer, B., Sinha, B., Day, D. A., Andreae, M. O., Jimenez, J. L., Gallagher, M., Kreidenweis, S. M., Bertram, A. K., and Pöschl, U.: High concentrations of biological aerosol particles and ice nuclei during and after rain, Atmos. Chem. Phys., 13, 6151-6164, doi:10.5194/acp-13-6151-2013, 2013.

Kamphus, M., Ettner-Mahl, M., Klimach, T., Drewnick, F., Keller, L., Cziczo, D. J., Mertes, S., Borrmann, S., and Curtius, J.: Chemical composition of ambient aerosol, ice residues and cloud droplet residues in mixed-phase clouds: single particle analysis during the Cloud and Aerosol Characterization Experiment (CLACE 6), Atmos. Chem. Phys., 10, 8077-8095, doi:10.5194/acp-10-8077-2010, 2010.

Kaye, P. H., Hirst, E., Greenaway, R. S., Ulanowski, Z., Hesse, E., DeMott, P. J., Saunders, C., and Connolly, P.: Classifying atmospheric ice crystals by spatial light scattering, Opt. Lett., 33, 1545-1547, doi:10.1364/OL.33.001545, 2008.

Kim, S. W. and Raynor, P. C.: A New Semivolatile Aerosol Dichotomous Sampler, Ann. Occup. Hyg., 53, 239-248, doi:10.1093/annhyg/mep008, 2009.

Knopf, D. A., Alpert, P. A., Wang, B., O’Brien, R. E., Kelly, S. T., Laskin, A., Gilles, M. K., and Moffet, R. C.: Microspectroscopic imaging and characterization of individually identified ice nucleating particles from a case field study, J. Geophys. Res. Atmos., 119, JD021866, doi:10.1002/2014JD021866, 2014.

Korolev, A. V., Isaac, G. A., Cober, S. G., Strapp, J. W., and Hallett, J.: Microphysical characterization of mixed-phase clouds, Q. J. Roy. Meteor. Soc., 129, 39-65, 2003.

Kulkarni, G., Pekour, M., Afchine, A., Murphy, D. M., and Cziczo, D. J.: Comparison of experimental and numerical studies of the performance characteristics of a pumped coun- terflow virtual impactor, Aerosol Sci. Tech., 45, 382-392, doi:10.1080/02786826.2010.539291, 2011.

Kulkarni, G., Nandasiri, M., Zelenyuk, A., Beranek, J., Madaan, N., Devaraj, A., Shutthanandan, V., Thevuthasan, S., and Varga, T.: Effects of crystallographic properties on the ice nucleation properties of volcanic ash particles, Geophys. Res. Lett., 42, 3048-3055, doi:10.1002/2015GL063270, 2015.

Kupiszewski, P., Weingartner, E., Vochezer, P., Schnaiter, M., Bigi, A., Gysel, M., Rosati, B., Toprak, E., Mertes, S., and Baltensperger, U.: The Ice Selective Inlet: a novel technique for exclusive extraction of pristine ice crystals in mixed-phase clouds, Atmos. Meas. Tech., 8, 3087-3106, doi:10.5194/amt-8-30872015, 2015.

Lawson, R.P., Stamnes, K., Stamnes, J., Zmarzly, P., Koskuliks, J., Roden, C., Mo, Q., Carrithers, M., and Bland, G.L.: Deployment of a tethered-balloon system for microphysics and radiative measurements in mixed-phase clouds at Ny-Ålesund and south pole. J. Atmos. Ocean. Technol. 28, 656-670, doi:10.1175/2010JTECHA1439.1, 2011.

Matsuki, A., Schwarzenboeck, A., Venzac, H., Laj, P., Crumeyrolle, S., and Gomes, L.: Cloud processing of mineral dust: direct comparison of cloud residual and clear sky particles during AMMA aircraft campaign in summer 2006, Atmos. Chem. Phys., 10, 1057-1069, doi:10.5194/acp-10-1057-2010, 2010.

Mertes, S., Schwarzenböck, A., Laj, P., Wobrock, W., Pichon, J. M., Orsi, G., and Heintzenberg, J.: Changes of cloud microphysical properties during the transition from supercooled to mixed-phase conditions during CIME, Atmos. Res., 58, 267294, doi:10.1016/S0169-8095(01)00095-3, 2001.

Miles, N. L., Verlinde, J., and Clothiaux, E. E.: Cloud droplet size distributions in low-level stratiform clouds, J. Atmos. Sci., 57, 295-311, doi:10.1175/15200469(2000)057<0295:CDSDIL>2.0.CO;2, 2000.

Möhler, O., Stetzer, O., Schaefers, S., Linke, C., Schnaiter, M., Tiede, R., Saathoff, H., Krämer, M., Mangold, A., Budz, P., Zink, P., Schreiner, J., Mauersberger, K., Haag, W., Kärcher, B., and Schurath, U.: Experimental investigation of homogeneous freezing of sulphuric acid particles in the aerosol chamber AIDA, Atmos. Chem. Phys., 3, 211-223, doi:10.5194/acp-3-211-2003, 2003.

Möhler, O., Linke, C., Saathoff, H., Schnaiter, M., Wagner, R., Mangold, A., Kramer, M., and Schurath, U.: Ice nucleation on flame soot aerosol of different organic carbon content, Meteorol. Z., 14, 477-484, doi:10.1127/0941-2948/2005/0055, 2005a.

Möhler, O., Büttner, S., Linke, C., Schnaiter, M., Saathoff, H., Stetzer, O., Wagner, R., Kramer, M., Mangold, A., Ebert, V., and Schurath, U.: Effect of sulphuric acid coating on heterogeneous ice nucleation by soot aerosol particles, J. Geophys. Res., 110, D11210, doi:10.1029/2004JD005169, 2005b.

Möhler, O., Field, P. R., Connolly, P., Benz, S., Saathoff, H., Schnaiter, M., Wagner, R., Cotton, R., Krämer, M., Mangold, A., and Heymsfield, A. J.: Efficiency of the deposition mode ice nucleation on mineral dust particles, Atmos. Chem. Phys., 6, 30073021, doi:10.5194/acp-6-3007-2006, 2006.

Murray, B. J., O’Sullivan, D., Atkinson, J. D., and Webb, M. E.: Ice nucleation by particles immersed in supercooled cloud droplets, Chem. Soc. Rev., 41, 6519-6554, doi:10.1039/c2cs35200a, 2012. 
Niemand, M., Möhler, O., Vogel, B., Vogel, H., Hoose, C., Connolly, P., Klein, H., Bingemer, H., DeMott, P., and Skrotzki, J.: A particle-surface-area-based parameterization of immersion freezing on desert dust particles, J. Atmos. Sci., 69, 3077-3092, doi:10.1175/Jas-D-11-0249.1, 2012.

Noone, K., Ogren, J. A., Heintzenberg, J., Charlson, R. J., and Covert, D. S.: Design and calibration of a counterflow virtual impactor for sampling of atmospheric fog and cloud droplets, Aerosol Sci. Technol., 8, 235-244, doi:10.1080/02786828808959186, 1988.

Noone, K. J., Öström, E., Ferek, R. J., Garrett, T., Hobbs, P. V., Johnson, D. W., Taylor, J. P., Russell, L. M., Fragan, R. C., Sein feld, J. H., O’Dowd, C. D., Smith, M. H., Durkee, P. A., Nielsen, K., Hudson, J. G., Pockalny, R. A., de Bock, L., van Grieken, R. E., Gasparovic, R. F., and Brooks, I.: A case study of ships forming and not forming tracks in moderately polluted clouds, J. Atmos. Sci., 57, 2729-2747, doi:10.1175/15200469(2000)057<2729:ACSOSF>2.0.CO;2, 2000.

Ogren, J. A., Heintzenberg, J., and Charlson, R. J.: In situ sampling of clouds with a droplet to aerosol converter, Geophys. Res. Lett., 12, 121-124, doi:10.1029/GL012i003p00121, 1985.

O’Sullivan, D., Murray, B. J., Ross, J. F., Whale, T. F., Price, H. C., Atkinson, J. D., Umo, N. S., and Webb, M. E.: The relevance of nanoscale biological fragments for ice nucleation in clouds, Sci. Rep., 5, 8082, doi:10.1038/srep08082, 2015.

Pekour, M. S. and Cziczo, D. J.: Wake capture, parti cle breakup, and other artifacts associated with counterflow virtual impaction, Aerosol Sci. Tech., 45, 758-764, doi:10.1080/02786826.2011.558942, 2011.

Pratt, K. A., DeMott, P. J., French, J. R., Wang, Z., Westphal, D. L., Heymsfield, A. J., Twohy, C. H., Prenni, A. J., and Prather, K. A.: In situ detection of biological particles in cloud ice-crystals, Nat. Geosci., 2, 397-400, doi:10.1038/ngeo521, 2009.

Prenni, A. J., Petters, M. D., Kreidenweis, S. M., Heald, C. L., Martin, S. T., Artaxo, P., Garland, R. M., Wollny, A. G., and Poschl, U.: Relative roles of biogenic emissions and Saharan dust as ice nuclei in the Amazon basin, Nat. Geosci., 2, 401-404, doi:10.1038/ngeo517, 2009.

Richardson, M. S., DeMott, P. J., Kreidenweis, S. M., Cziczo, D. J., Dunlea, E. J., Jimenez, J. L., Thomson, D. S., Ashbaugh, L. L., Borys, R. D., Westphal, D. L., Casuccio, G. S., and Lersch, T. L.: Measurements of heterogeneous ice nuclei in the western United States in springtime and their relation to aerosol characteristics, J. Geophys. Res., 112, D02209, doi:10.1029/2006JD007500, 2007.

Russell, L. M., Noone, K. J., Ferek, R. J., Pockalny, R. A., Flagan, R. C., and Seinfeld, J. H.: Combustion organic aerosol as cloud condensation nuclei in ship tracks, J. Atmos. Sci., 57, 2591-2606, doi:10.1175/15200469(2000)057<2591:COAACC>2.0.CO;2, 2000.

Schnaiter, M., Järvinen, E., Vochezer, P., Abdelmonem, A., Wagner, R., Jourdan, O., Mioche, G., Shcherbakov, V. N., Schmitt, C. G., Tricoli, U., Ulanowski, Z., and Heymsfield, A. J.: Cloud chamber experiments on the origin of ice crystal complexity in cirrus clouds, Atmos. Chem. Phys., 16, 5091-5110, doi:10.5194/acp16-5091-2016, 2016.

Schwarzenböck, A., Heintzenberg, J., and Mertes, S.: Incorporation of aerosol particles between 25 and $850 \mathrm{~nm}$ into cloud elements: measurements with a new complementary sampling system, At- mos. Res. 52, 241-260, doi:10.1016/S0169-8095(99)00034-4, 2000.

Shingler, T., Dey, S., Sorooshian, A., Brechtel, F. J., Wang, Z., Metcalf, A., Coggon, M., Mülmenstädt, J., Russell, L. M., Jonsson, H. H., and Seinfeld, J. H.: Characterisation and airborne deployment of a new counterflow virtual impactor inlet, Atmos. Meas. Tech., 5, 1259-1269, doi:10.5194/amt-5-1259-2012, 2012.

Slowik, J. G., Cziczo, D. J., and Abbatt, J. P. D.: Analysis of cloud condensation nuclei composition and growth kinetics using a pumped counterflow virtual impactor and aerosol mass spectrometer, Atmos. Meas. Tech., 4, 1677-1688, doi:10.5194/amt4-1677-2011, 2011.

TSI, Model 3010: Instruction Manual for Condensation Particle Counter, Model 3010, St. Paul, MN: TSI Incorporated, 1996.

Twohy, C. H. and Anderson, J. R.: Droplet nuclei on nonprecipitating clouds: composition and size matter, Environ. Res. Lett., 3, 045002, doi:10.1088/1748-9326/3/4/045002, 2008.

Twohy, C. H., Schanot, A. J., and Cooper, W. A.: Measurement of condensed water content in liquid and ice clouds using an airborne counterflow virtual impactor, J. Atmos. Oceanic Technol., 14, 197-202, doi:10.1175/15200426(1997)014<0197:MOCWCI>2.0.CO;2, 1997.

Twohy, C. H., Hudson, J. G., Yum, S.-S., Anderson, J. R., Durlak, S. K., and Baumgardner D.: Characteristics of cloudnucleating aerosols in the Indian Ocean region, J. Geophys. Res., 106, 28699-28710, doi:10.1029/2000JD900779, 2001.

Vochezer, P., Järvinen, E., Wagner, R., Kupiszewski, P., Leisner, T., and Schnaiter, M.: In situ characterization of mixed phase clouds using the Small Ice Detector and the Particle Phase Discriminator, Atmos. Meas. Tech., 9, 159-177, doi:10.5194/amt-9-1592016, 2016.

Vogel, A. L., Äijälä, M., Brüggemann, M., Ehn, M., Junninen, H., Petäjä, T., Worsnop, D. R., Kulmala, M., Williams, J., and Hoffmann, T.: Online atmospheric pressure chemical ionization ion trap mass spectrometry (APCI-IT-MSn) for measuring organic acids in concentrated bulk aerosol - a laboratory and field study, Atmos. Meas. Tech., 6, 431-443, doi:10.5194/amt-6-431-2013, 2013.

Wagner, R., Benz, S., Bunz, H., Möhler, O., Saathoff, H., Schnaiter, M., Leisner, T., and Ebert, V.: Infrared optical constants of highly diluted sulfuric acid solution droplets at cirrus temperatures, J. Phys. Chem. A, 112, 11661-11676, doi:10.1021/jp8066102, 2008.

Wex, H., Augustin-Bauditz, S., Boose, Y., Budke, C., Curtius, J., Diehl, K., Dreyer, A., Frank, F., Hartmann, S., Hiranuma, N., Jantsch, E., Kanji, Z. A., Kiselev, A., Koop, T., Möhler, O., Niedermeier, D., Nillius, B., Rösch, M., Rose, D., Schmidt, C., Steinke, I., and Stratmann, F.: Intercomparing different devices for the investigation of ice nucleating particles using Snomax ${ }^{\circledR}$ as test substance, Atmos. Chem. Phys., 15, 14631485, doi:10.5194/acp-15-1463-2015, 2015.

Wilson, T. W., Ladino, L. A., Alpert, P. A., Breckels, M. N., Brooks, I. M., Browse, J., Burrows, S. M., Carslaw, K. S., Huffman, J. A., Judd, C., Kilthau, W. P., Mason, R. H., McFiggans, G., Miller, L. A., Najera, J. J., Polishchuk, E., Rae, S., Schiller, C. L., Si, M., Temprado, J. V., Whale, T. F., Wong, J. P., Wurl, O., Yakobi-Hancock, J. D., Abbatt, J. P., Aller, J. Y., Bertram, A. K., Knopf, D. A., and Murray, B. J.: A marine biogenic source 
of atmospheric ice-nucleating particles, Nature, 525, 234-238, doi:10.1038/nature14986, 2015.

Worringen, A., Kandler, K., Benker, N., Dirsch, T., Mertes, S., Schenk, L., Kästner, U., Frank, F., Nillius, B., Bundke, U., Rose, D., Curtius, J., Kupiszewski, P., Weingartner, E., Vochezer, P., Schneider, J., Schmidt, S., Weinbruch, S., and Ebert, M.: Singleparticle characterization of ice-nucleating particles and ice particle residuals sampled by three different techniques, Atmos. Chem. Phys., 15, 4161-4178, doi:10.5194/acp-15-4161-2015, 2015.
Zelenyuk, A., Imre, D., Wilson, J., Zhang, Z., Wang, J., and Mueller, K.: Airborne single particle mass spectrometers (SPLAT II \& miniSPLAT) and new software for data visualization and analysis in a geo-spatial context, J. Am. Soc. Mass Spectrom., 26, 257-270, doi:10.1007/s13361-014-1043-4, 2015. 